\title{
NIST Weather Station for Photovoltaic and Building System Research
}

Matthew T. Boyd

This publication is available free of charge from: http://dx.doi.org/10.6028/NIST.TN.1913
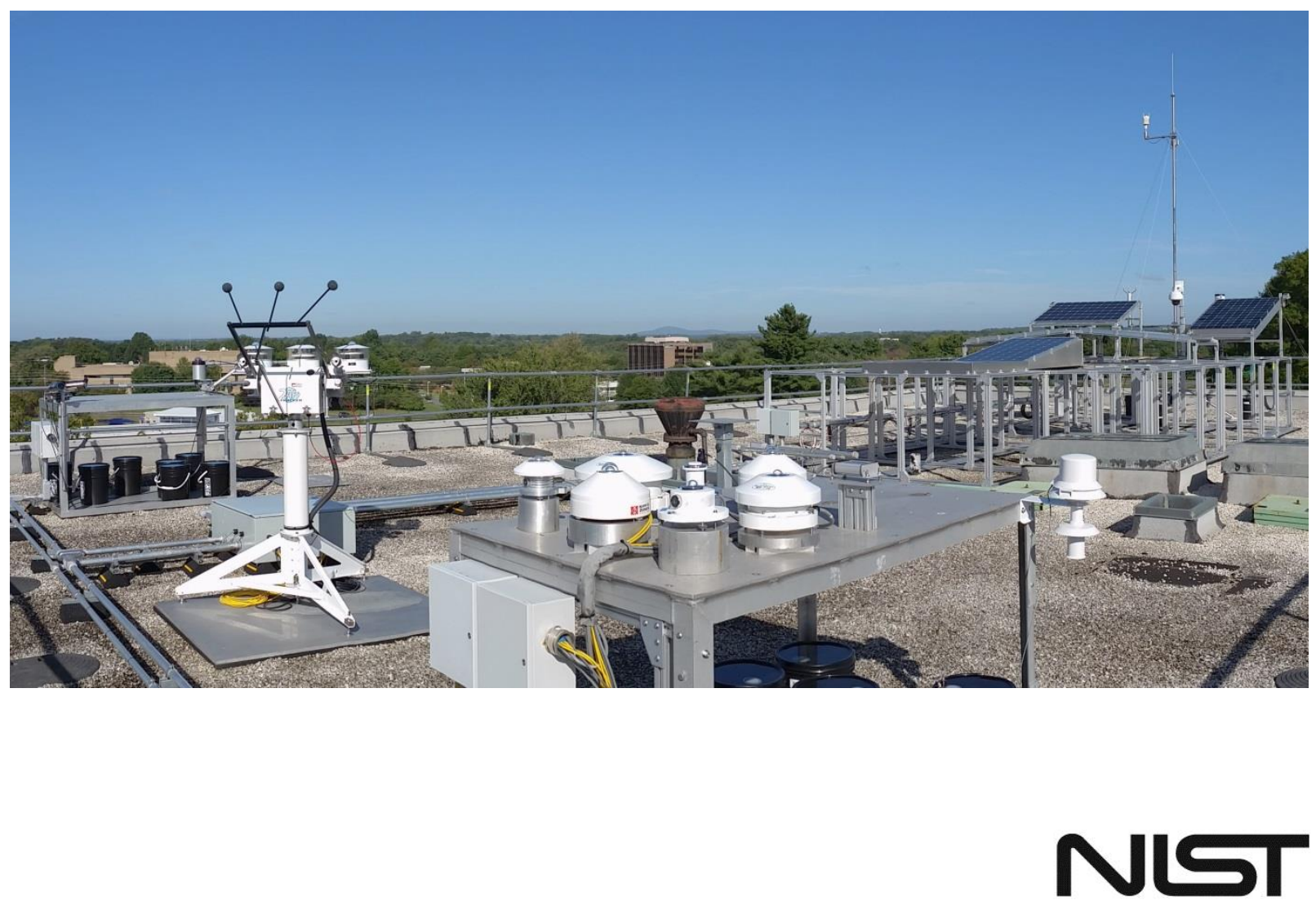

National Institute of Standards and Technology U.S. Department of Commerce 

NIST Technical Note 1913

\title{
NIST Weather Station for Photovoltaic and Building System Research
}

\author{
Matthew T. Boyd \\ Energy and Environment Division \\ Engineering Laboratory
}

This publication is available free of charge from:

http://dx.doi.org/10.6028/NIST.TN.1913

March 2016

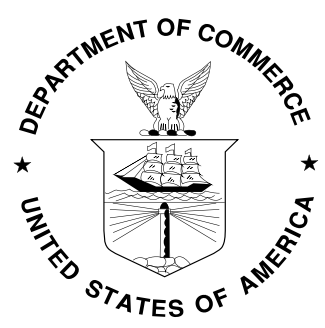

U.S. Department of Commerce Penny Pritzker, Secretary

National Institute of Standards and Technology Willie May, Under Secretary of Commerce for Standards and Technology and Director 
Certain commercial entities, equipment, or materials may be identified in this document in order to describe an experimental procedure or concept adequately. Such identification is not intended to imply recommendation or endorsement by the National Institute of Standards and Technology, nor is it intended to imply that the entities, materials, or equipment are necessarily the best available for the purpose.

National Institute of Standards and Technology Technical Note 1913

Natl. Inst. Stand. Technol. Tech. Note 1913, 43 pages (March 2016) CODEN: NTNOEF

This publication is available free of charge from: http://dx.doi.org/10.6028/NIST.TN.1913 


\section{Preface}

This effort was conducted by the Energy and Environment Division in the Engineering Laboratory at the National Institute of Standards and Technology (NIST). This document describes the meteorological instruments and data acquisition system (DAS) at a research-grade weather station on the NIST campus in Gaithersburg, Maryland, USA, including the rationale for the selected instruments, data loggers, control software, and supplementary devices. The intended audiences are researchers who wish to use the gathered data, including the compiled weather files, for analysis and modeling of photovoltaic (PV) systems, building energy, or meteorological values, as well as designers who are interested in building a similar research-grade weather station. Modelers and analysts who are interested in using the data in collaboration on new research before a public data portal is available can contact the author.

\section{Author Information}

Matthew T. Boyd

Mechanical Engineer

National Institute of Standards and Technology

Engineering Laboratory

100 Bureau Drive, Mailstop 8632

Gaithersburg, MD 20899-8632

Tel.: 301-975-6444

Email: matthew.boyd@nist.gov 


\begin{abstract}
A weather station has been constructed on the Gaithersburg, Maryland campus of the National Institute of Standards and Technology (NIST) as part of a research effort to assess performance of photovoltaic and building systems. This weather station includes research-grade instrumentation to measure all standard meteorological quantities plus various additional solar irradiance spectral bands, full spectrum curves, and directional components using multiple irradiance sensor technologies. Reference photovoltaic (PV) modules are also monitored on site to provide comprehensive baseline measurements for the PV arrays on campus. Images of the whole sky are captured, along with images of the instrumentation and reference modules to document any obstructions or anomalies. Nearly all measurements are sampled and saved every 1 second, with monitoring having started August 1, 2014. This report describes the instrumentation approach to measure the meteorological and photovoltaic quantities and acquire the images for use in computer model validation or weather monitoring.
\end{abstract}

\title{
Keywords
}

meteorology, weather station, data acquisition, solar, photovoltaic 


\section{Table of Contents}

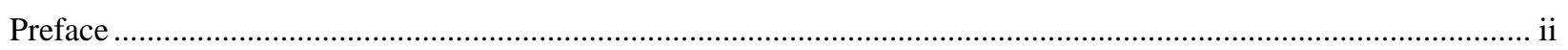

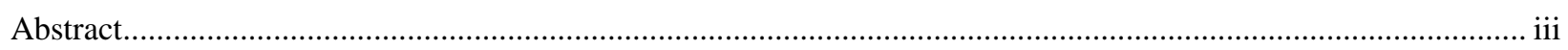

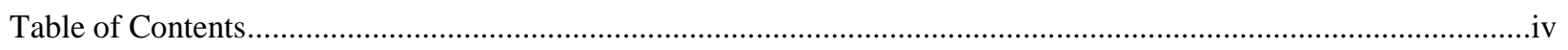

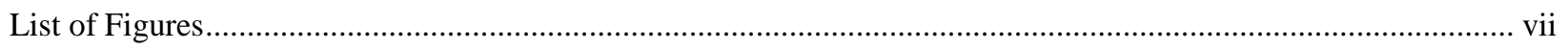

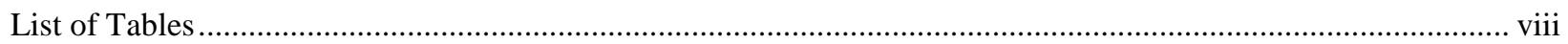

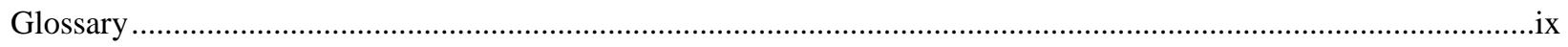

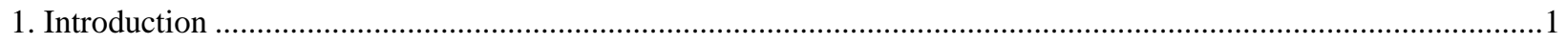



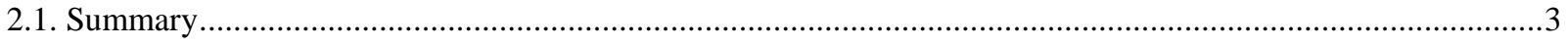

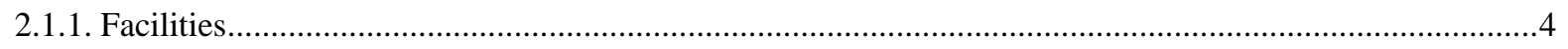



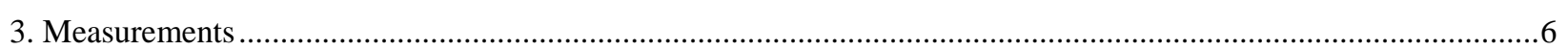

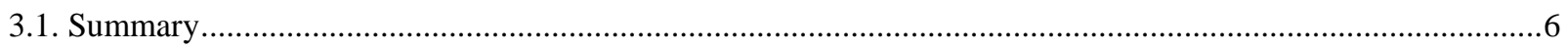

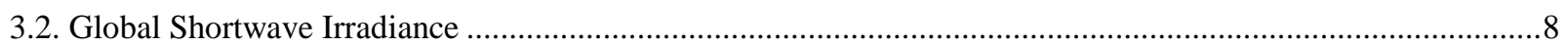



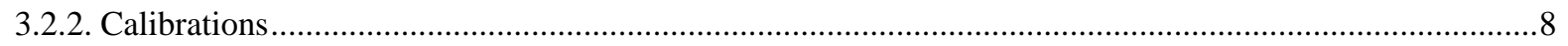

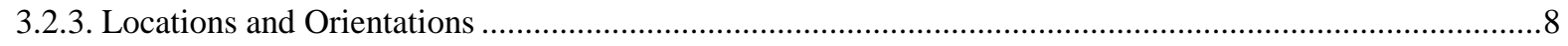

3.2.4. Mounting and Alignment ................................................................................................................

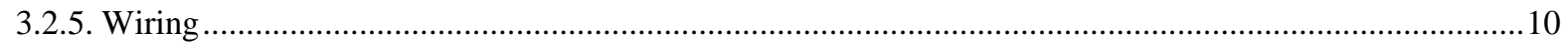

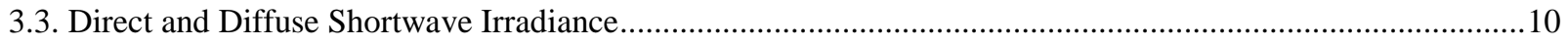

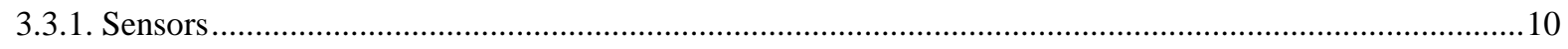





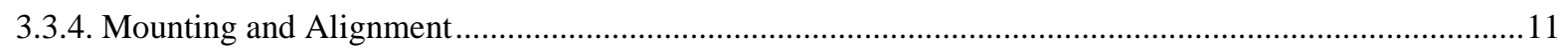

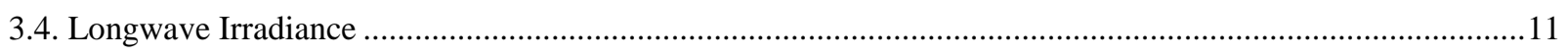



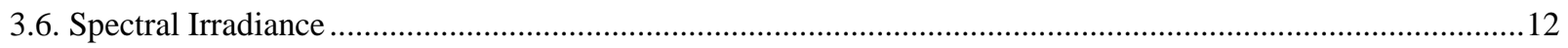

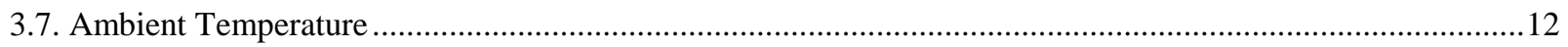

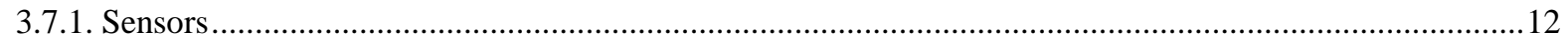

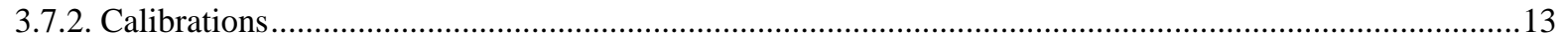

3.7.3. Locations and Orientations ………………..................................................................................13

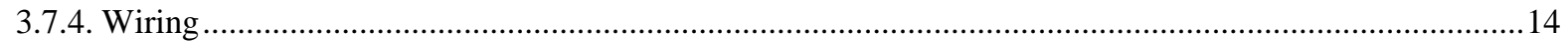

3.8. Wind …… 


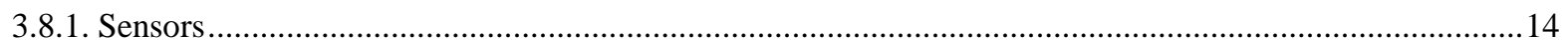

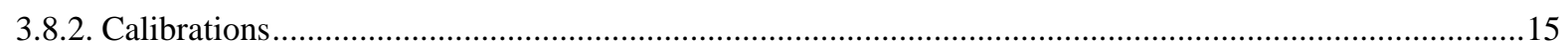

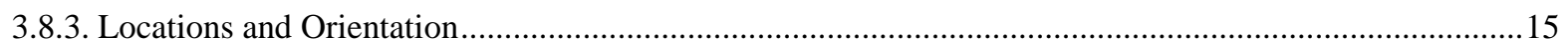

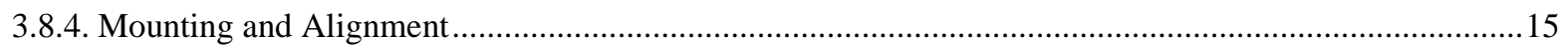

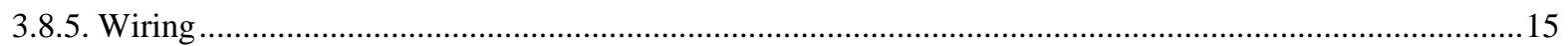



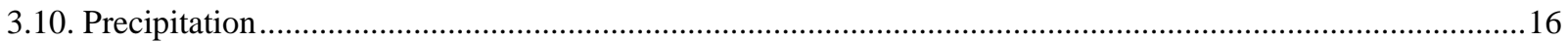

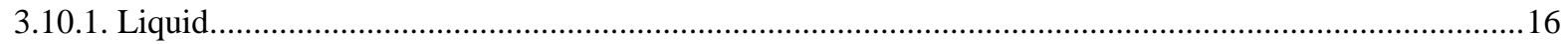

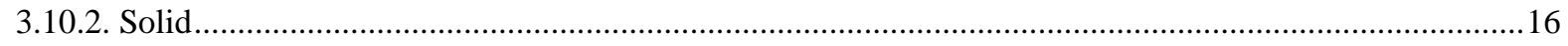

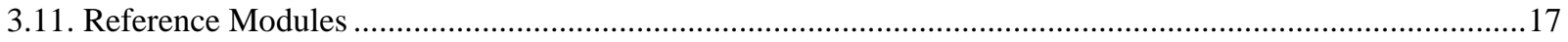

3.12. Module Temperature …………....................................................................................................19



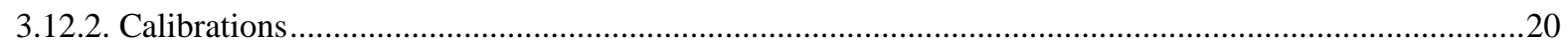

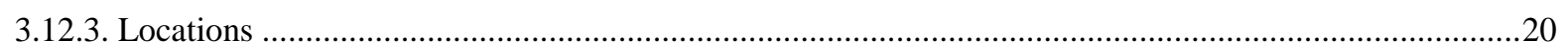



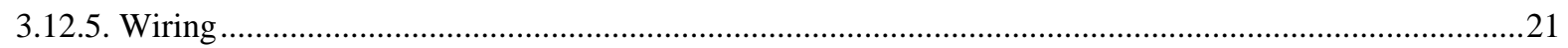

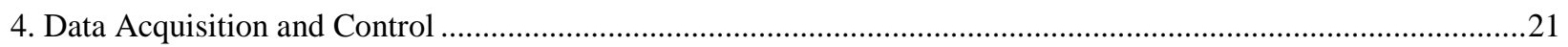

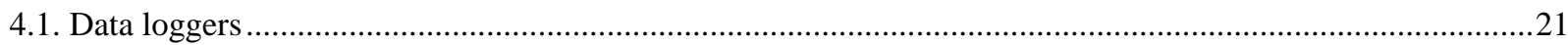

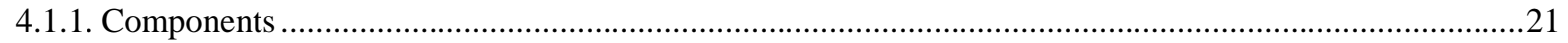

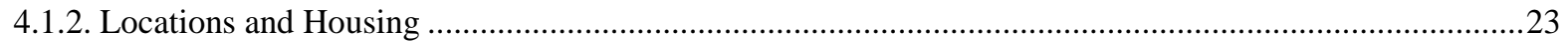

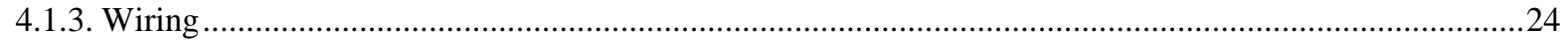

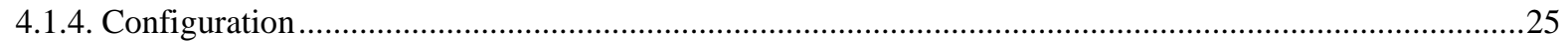



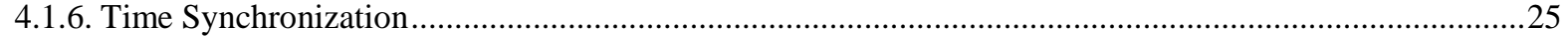

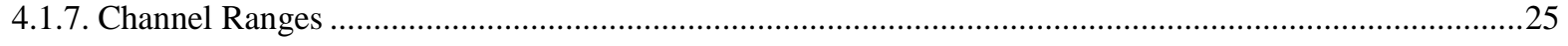

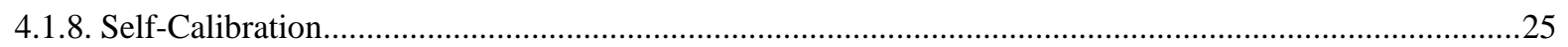

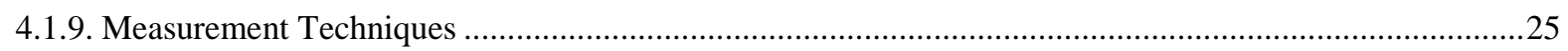

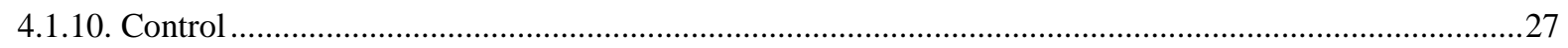

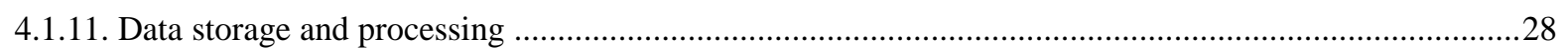

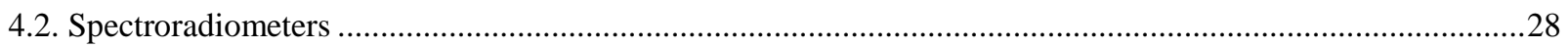



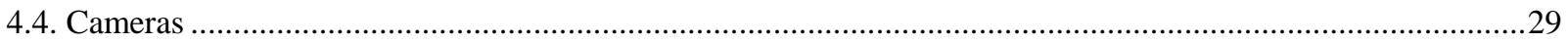

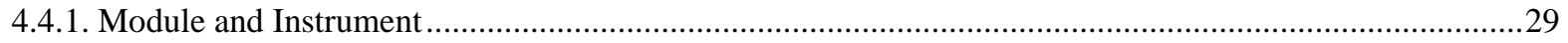



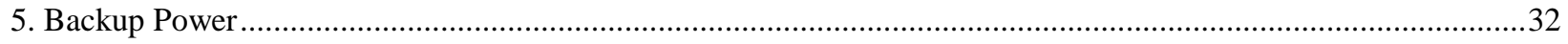




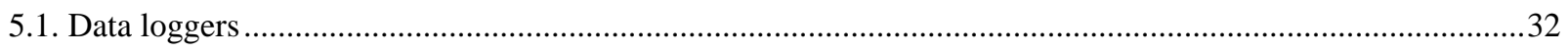

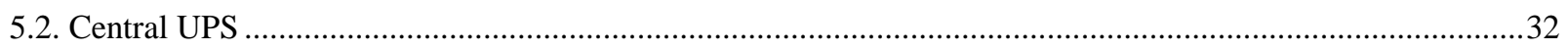

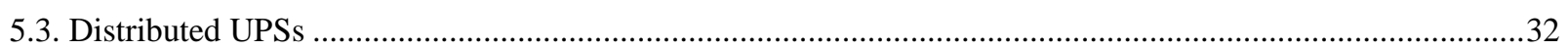

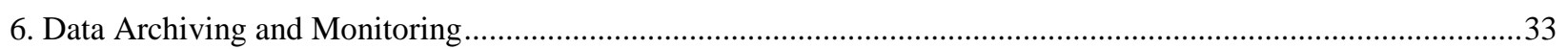

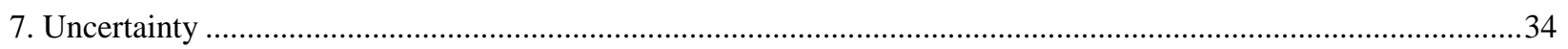

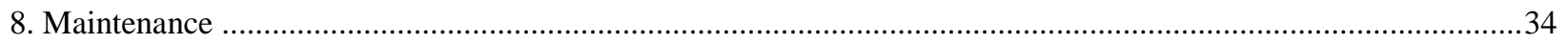



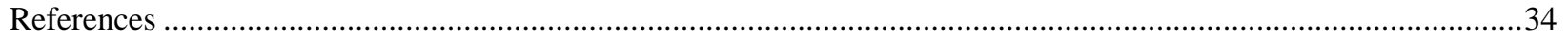

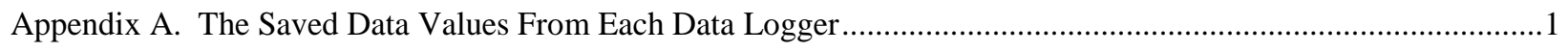

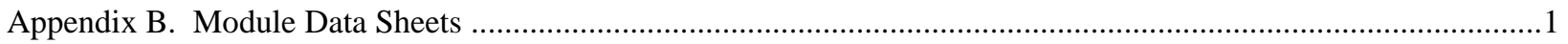




\section{List of Figures}

Figure 1-1 A map of the weather station, instrumented PV arrays, and the NZERTF on the NIST campus in Gaithersburg, Maryland. The vertical edge of this image corresponds to $1 \mathrm{~km}(0.6$ miles or $3300 \mathrm{ft}) \ldots \ldots .1$

Figure 1-2 Weather Station.

Figure 2-1 Diagram of the weather station layout. The red circles on the reference modules show the locations of

the modules' backsheet surface temperature measurements. ............................................................

\section{2}

Figure 2-2 Preliminary shading model of weather station showing an unshaded period on Dec. 21 at 09:24 EST .....6

Figure 3-1 The east table with the GHI measuring pyranometers and silicon irradiance sensor mounted on it. Also shown are the spectroradiometers, UV radiometers, and the ambient temperature sensor (upper right)...9

Figure 3-2 Flat-plate silicon irradiance sensors measuring the POA irradiances on their respective reference modules .

Figure 3-3 The pyrheliometers mounted on the solar tracker above the sun sensor and below the horizontal diffusemeasuring pyranometers (left and right) and IR measuring pyrgeometer (center). The black balls shade the three horizontal instruments.

Figure 3-4 The temperature sensing probe in the aspirated radiation shield used to measure the outdoor ambient air temperature

Figure 3-5 The weather transmitter near the top of the instrument mast ............................................................ 14

Figure 3-6 The lower ultrasonic wind sensor (left) and heated tipping bucket rain gauge (right) on the lower

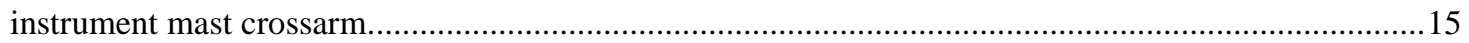

Figure 3-8 The snow sensor that measures snow depth ....................................................................................... 17

Figure 3-9 The reference modules installed at the weather station................................................................ 18

Figure 3-10 A visual comparison of the three types of module temperature sensors used for the reference modules and at the arrays: the RTD used at the Canopy, Roof Tilted, and Ground Arrays (left), the RTD used for the corresponding reference modules (center), and the thermocouple used at Roof Horizontal and NZERTF arrays and all of the reference modules (right).

Figure 3-11 An RTD mounted on the back of a module using thermally conductive epoxy and an adhesive film overlay

Figure 4-1 The data acquisition enclosure at the weather station showing the data loggers, measurement and communication peripherals, battery backups, relays, and power converters and distribution blocks ......22

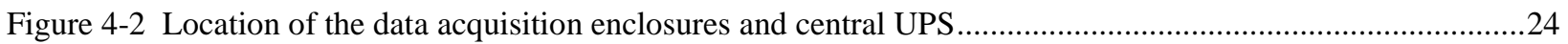

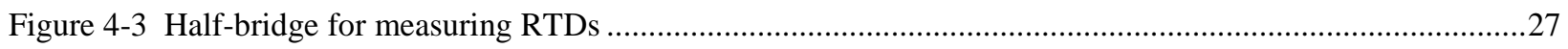

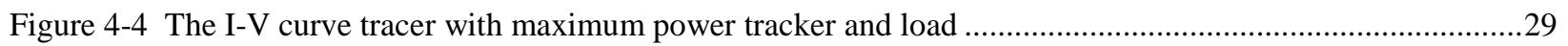

Figure 4-5 The PTZ camera that records images of the instruments and NZERTF PV array ...................................30

Figure 4-7 The all sky camera with the ambient temperature and humidity sensor installed on a custom mount on

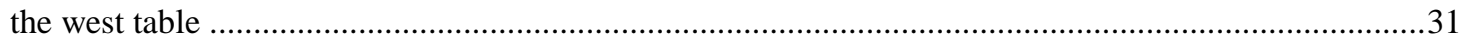

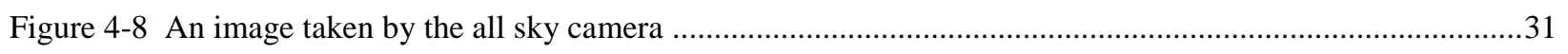

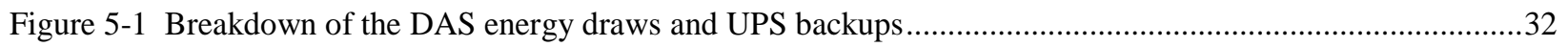

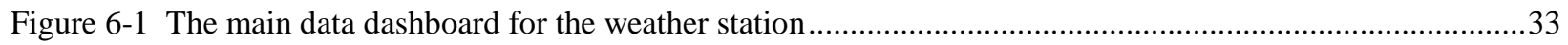

Figure B-1 Picture of Horizontal PV Reference Module Nameplate ……........................................................ B-1

Figure B-2 Manufacturer Datasheet for the $5^{\circ}, 10^{\circ}$, and $20^{\circ}$ Tilted PV Reference Modules .................................. B-2

Figure B-3 Manufacturer Datasheet for the $18.4^{\circ}$ PV Reference Module ............................................................... B-3 


\section{List of Tables}

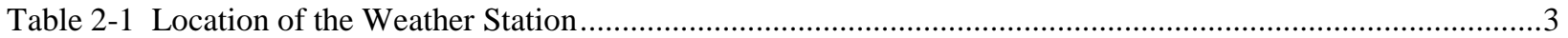

Table 3-1 Summary of the Measurements and Respective Instruments Installed at the Weather Station ...................6

Table 3-2 Summary of Reference Modules ...............................................................................................18

Table A-1 The Saved Data Values From Each Data Logger .............................................................................. 


\begin{tabular}{|c|c|}
\hline Glossary & \\
\hline$A C$ & alternating current \\
\hline$B O R C A L$ & Broadband Outdoor Radiometer Calibration \\
\hline bps & bits per second \\
\hline$C W$ & clockwise \\
\hline$D A S$ & data acquisition system \\
\hline$D C$ & direct current \\
\hline DHI & diffuse horizontal irradiance \\
\hline DNI & direct normal irradiance \\
\hline$D o D$ & Department of Defense \\
\hline$D S T$ & daylight saving time \\
\hline EMI & electromagnetic interference \\
\hline$F A A$ & Federal Aviation Administration \\
\hline GHI & global horizontal irradiance \\
\hline$I-V$ & current-voltage \\
\hline$I R$ & infrared \\
\hline$L S T$ & local standard time \\
\hline mono $c$-si & monocrystalline silicon \\
\hline$N E$ & northeast \\
\hline$N W$ & northwest \\
\hline NIST & National Institute of Standards and Technology \\
\hline$N R E L$ & National Renewable Energy Laboratory \\
\hline$N S R D B$ & National Solar Radiation Database \\
\hline$N Z E R T F$ & Net-Zero Energy Residential Test Facility \\
\hline$P O A$ & plane-of-array \\
\hline$P o E$ & Power over Ethernet \\
\hline$P T Z$ & pan-tilt-zoom \\
\hline$P V$ & photovoltaic \\
\hline$R T D$ & resistance temperature detector \\
\hline$U P S$ & uninterrupted power supply \\
\hline$U T C$ & Coordinated Universal Time \\
\hline UTR & uniform temperature reference \\
\hline$U V$ & ultraviolet \\
\hline$V A C$ & volts, alternating current \\
\hline$V D C$ & volts, direct current \\
\hline$V D V$ & Vista Data Vision \\
\hline$V I$ & virtual instrument \\
\hline$\alpha$ & temperature coefficient of resistance \\
\hline$\Omega$ & ohms \\
\hline
\end{tabular}




\section{Introduction}

A weather station was constructed on the National Institute of Standards and Technology (NIST) campus in Gaithersburg Maryland, with monitoring commencing on August 1, 2014. The primary purpose of this weather station is to support research being conducted to characterize photovoltaic module and array performance as well as research on energy use and indoor environmental quality in buildings. An aerial view of the location is shown in Figure 1-1, which also includes the locations of the three largest PV arrays and the Net-Zero Energy Residential Test Facility (NZERTF), a laboratory on the NIST campus used for residential building research.

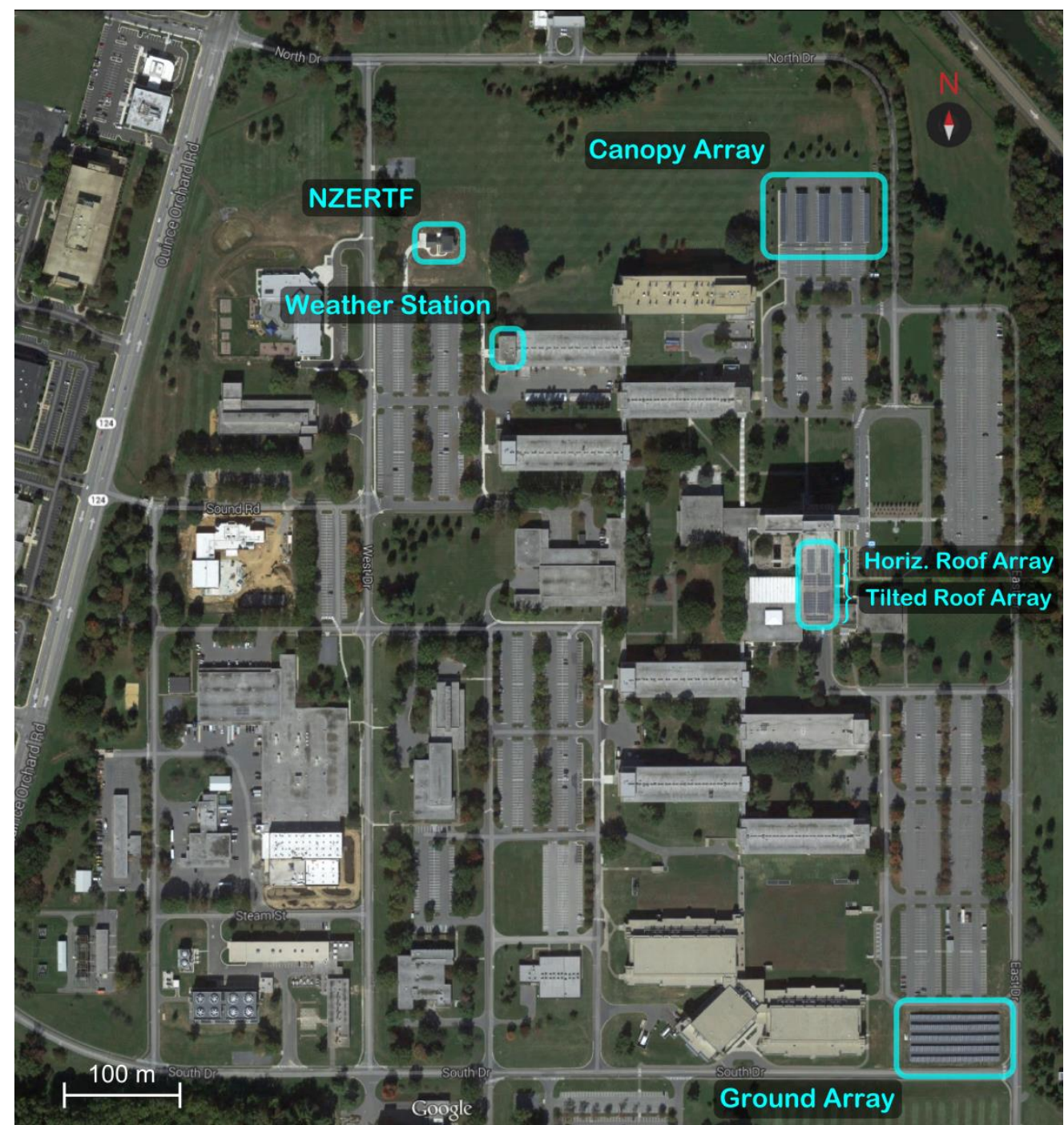

Figure 1-1 An aerial view of the weather station, instrumented PV arrays, and the NZERTF on the NIST campus in Gaithersburg, Maryland. The vertical edge of this image corresponds to $1 \mathrm{~km}(0.6$ miles or $3300 \mathrm{ft}$ ) 
Research-grade (i.e., low uncertainty) sensors are installed, as shown in Figure 1-2, to measure various meteorological quantities, including:

- $\quad$ direct normal irradiance (DNI)

- diffuse horizontal irradiance (DHI)

- global horizontal irradiance (GHI)

- $\quad$ infrared (IR) irradiance (net and total)

- ultraviolet (UV) irradiance (A, B, and total)

- $\quad$ spectral irradiance curves

- snow depth

- $\quad$ wind speed and direction

- humidity

- precipitation

- barometric pressure

- hail count

- ambient temperature



Figure 1-2 Weather Station

The data acquisition system (DAS) saves measurement values every 1 second along with the status of the solar tracker and other components. A current-voltage (I-V) tracer with a maximum power tracker and load saves curve traces from reference modules installed in the orientations of the modules in each of the PV arrays on campus every 1 minute, along with one-minute averaged maximum power measurements from one-second samples. Cameras were also installed that capture images of the entire sky every 8 seconds and close-up images of the instrumentation, reference modules, and NZERTF PV array every 5 minutes.

This weather station was created to provide supplementary data to the campus photovoltaic (PV) array and NZERTF DASs, as described in [1] and [2], respectively, for modeling and validation purposes. The station also helps to address the needs of the PV community for long-term, high accuracy, sub-minute data sets from calibrated, wellmaintained and documented systems in a variable weather environment, as expressed in [3], [4], [5], and [6]. 
The closest weather stations that have Class I designations according to the National Solar Radiation Database (NSRDB) [7] are located at Washington Dulles International Airport (KIAD), which is $29.2 \mathrm{~km}$ (18.2 mi) southwest of NIST, and Baltimore-Washington International Airport (KBWI), which is $47.6 \mathrm{~km} \mathrm{(29.6} \mathrm{mi)} \mathrm{east} \mathrm{of} \mathrm{NIST.} \mathrm{These}$ two weather stations are Automated Surface Observing Systems (ASOS) cooperatively run by the National Oceanic and Atmospheric Administration (NOAA), Federal Aviation Administration (FAA), and the Department of Defense (DoD) [8].

\section{Overview}

\subsection{Summary}

The NIST weather station is located in Gaithersburg, Maryland in the United States, which is in the Eastern Time Zone (-5 hours from Coordinated Universal Time (UTC)). The exact location of the weather station is given in Table $2-1$, which specifically is for the instruments on the solar tracker, with elevation being the height above sea level.

Table 2-1 Location of the Weather Station

\begin{tabular}{lc}
\hline Latitude $\left[{ }^{\circ} \mathrm{N}\right]$ & 39.1374 \\
Longitude $\left[{ }^{\circ} \mathrm{E}\right]$ & -77.2187 \\
Elevation $^{*}[\mathrm{~m}]$ & 158 \\
\hline$*$
\end{tabular}

* Includes height of building (19.5 m)

The weather station is on a flat, white gravel roof of a five-story (above ground) building. The roof is surrounded by a free-standing ballasted railing and is accessible by a fixed ladder in the northeast corner of the roof. A jib crane was installed near the ladder for hoisting large objects up to the roof. The roof has a relatively unobstructed view of the sky, with the only significantly higher nearby object being a 14-story (above ground) building $305 \mathrm{~m} \mathrm{[1000 \textrm {ft } ]}$ southeast of the weather station, which occludes the sun in the early morning for approximately one hour after sunrise between November 8 and February 4.

The weather station is comprised of sun-tracking instruments and stationary instruments, reference modules, and cameras. Instruments that track the sun are installed on a single tracker while stationary instruments are installed on

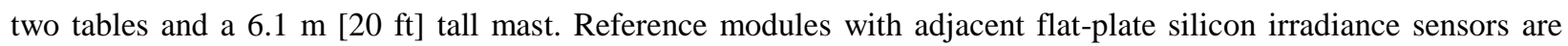
installed on a platform at the same orientations as the modules in the campus PV arrays. A diagram of the weather station layout is shown in Figure 2-1. 




Figure 2-1 Diagram of the weather station layout. The red circles on the reference modules show the locations of the modules' backsheet surface temperature measurements.

Data collection from most of the instruments started August 1, 2014, with the exceptions being the pan-tilt-zoom (PTZ) camera (Oct. 9, 2014), the reference modules (Nov. 5, 2014), the spectroradiometers (Dec. 1, 2014), the all sky camera (Dec. 7, 2014), and the fixed camera (Dec. 9, 2014).

\subsubsection{Facilities}

The solar tracker is a Kipp and Zonen 2AP Gear Drive with Sun Sensor ${ }^{1}$, with a tracking accuracy of $0.05^{\circ}$. The tracker is fitted with a rear mounting plate and a shading ball assembly for horizontal diffuse measurements. The tracker is mounted on a height extension tube and floor stand, with the floor stand anchored to a $122 \mathrm{~cm} \mathrm{x} 152 \mathrm{~cm} \mathrm{x}$ $1.9 \mathrm{~cm}$ (48 in. x 60 in. x 0.75 in.) aluminum plate on a foam rubber pad. The tracker is wired to a battery bank that provides over three and half days of backup power. The tracker is also wired to a data logger serial communication module using a separate cable through which the data logger polls the tracker via its RS-232 interface for its state and status information. The tracker, however, operates autonomously, using data from its sun sensor to correct its internal clock. A second tracker platform with a height of $91 \mathrm{~cm}(36 \mathrm{in}$.) was also installed for future expansion. This platform is affixed directly to the roof and can withstand higher wind loading.

The two tables for mounting stationary instruments are $1.07 \mathrm{~m}$ (42 in.) high, made of aluminum and ballasted atop foam rubber pads. The newer of the two has a top grating for more configurable mounting locations. All of the horizontal stationary radiometers are located on the east table, and are installed on separate platforms to normalize the heights of their sensor elements to within $1 \mathrm{~cm}(0.4$ in.) to minimize the instruments' mutual shading and sky occlusion.

\footnotetext{
1 Certain commercial equipment, instruments, or materials are identified in this paper to foster understanding. Such identification does not imply recommendation or endorsement by the National Institute of Standards and Technology, nor does it imply that the materials or equipment identified are necessarily the best available for the purpose.
} 
The $6.1 \mathrm{~m}$ (20 ft) tall, $5.1 \mathrm{~cm}$ (2 in.) diameter mast is a Campbell Scientific CM120 with crossbeams for mounting instruments at $1.78 \mathrm{~m}(5.8 \mathrm{ft})$ and $5.33 \mathrm{~m}(17.5 \mathrm{ft})$ above the roof. A lightning rod extends $71 \mathrm{~cm}(28 \mathrm{in}$.) above the top of the mast, which is electrically connected through the mast and bonded to the building's lightning ground via a lightning wire. The mast is anchored to three $61 \mathrm{~cm} \times 61 \mathrm{~cm} \times 2.5 \mathrm{~cm}$ (24 in. x 24 in. x 1 in.) aluminum plates on foam rubber pads with additional ballast and is supported using guy wires attached to eye bolt anchors in the roof.

The PV module platform is nominally $1.22 \mathrm{~m}$ (48 in.) high, with more northern modules mounted progressively higher to reduce shading. The platform height is high enough for easily moving about under the platform and accessing the modules' wiring and low enough for easily installing the modules and periodically cleaning them. The platform is constructed of extruded aluminum t-slot framing, which allows easy future reconfiguration.

Separate metal conduits are used for running signal, AC, and PV power cables to reduce electromagnetic interference (EMI). These conduits enter the roof through a single penetration and into a large enclosure. The cables are split off into other conduits running to pull boxes and conduit access ports at various locations on the roof, with cable groups in the main enclosure wrapped with metal foil shielded sleeving to reduce EMI. Aluminum conduit was chosen instead of PVC or steel to shield the cables from EMI and not rust. A second penetration has also been installed for future expansion.

\subsubsection{Shading}

The weather station is arranged in a manner to minimize shading on the instruments and modules. The railing surrounding the roof is at the minimum safe height of $1.07 \mathrm{~m} \mathrm{(42} \mathrm{in.),} \mathrm{and} \mathrm{this} \mathrm{height} \mathrm{determines} \mathrm{the} \mathrm{minimum}$ height of all of the instruments and modules in order for them to remain unshaded by the railing. The roof access ladder and jib crane, $1.41 \mathrm{~m}$ (56 in.) and $1.63 \mathrm{~m}$ (64 in.) high, respectively, were installed in the northeast corner of the roof to minimize their shading impact, which would occur in the summer months at sunrise.

The two tracker positions are located in the east-west middle of the roof to reduce the amount of time their longer early morning and late evening shadows are cast on the modules north of the trackers. They are in a north-south arrangement so they do not point at each other at sunrise and sunset and are separated by a distance that keeps the southern tracker from shading the northern one. The two tables, each with the same height as the railing, are arranged furthest south on both sides of the trackers to eliminate any shading on the tables coming from the south. Aluminum instrument platforms normalize the height of the different instruments on the tables to minimize their mutual shading and sky occlusion. The tops of these table instruments are just below the lowest sun-pointing instruments on the tracker, allowing the tracker instruments to 'see' just over the table instruments to the horizon.

North of the trackers and tables is the PV module platform, with a nominal height of $1.22 \mathrm{~m}$ (48 in.) This platform is positioned in the east-west middle of the roof to minimize any shading from the tracker in the early morning and late evening. The platform is separated from the northern tracker position by a distance that keeps the tracker from shading the closest module. Higher tilted modules are positioned north of lower tilted modules and at a progressively higher height to eliminate shading from more southern modules.

Farthest north on the roof is the $6.1 \mathrm{~m}(20 \mathrm{ft})$ tall instrument mast. This mast is also positioned in the east-west middle of the roof in line with the module platform. The lower crossbar positions the instruments mounted on it just above the closest modules. This mast position and configuration minimizes its shading on the module platform.

A CAD model of the weather station was created in SketchUp [9] to aid in optimizing the arrangements, as shown in Figure 2-2. For the final configuration, according to the model, the maximum amount of shading that occurs is 42 minutes after sunrise and 37 minutes before sunset, which happens on the day of the summer solstice (varying between Jun. 20 and Jun. 22), with most of the shading being on the tables. The least amount of daily shading that occurs is 4 minutes after sunrise and 5 minutes before sunset, which happens on the day of the winter solstice (varying between Dec. 20 and Dec. 23), with most of the shading being on the modules. 


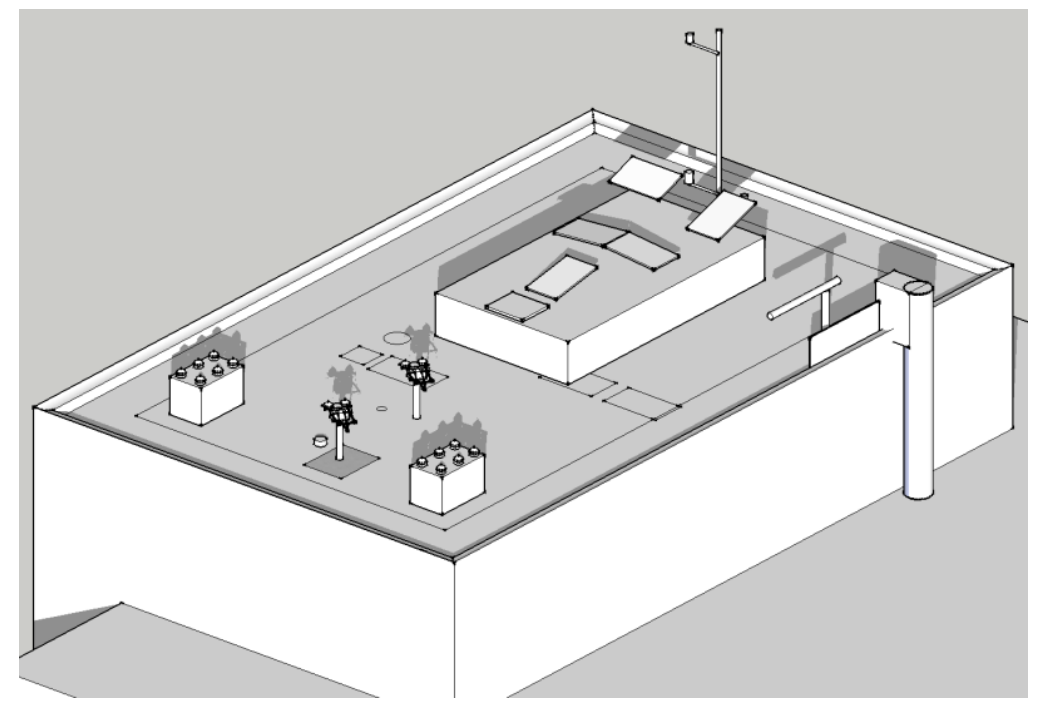

Figure 2-2 Preliminary shading model of weather station showing an unshaded period on Dec. 21 at 09:24 EST

\section{Measurements}

\subsection{Summary}

The measurements at the weather station and their corresponding instrument or sensor are summarized in Table 3-1. A complete listing of the saved data values is provided in Appendix A.

Table 3-1 Summary of the Measurements and Respective Instruments Installed at the Weather Station

\begin{tabular}{|c|c|c|}
\hline Measurement & Instrument/Sensor & Make/Model \\
\hline Ambient Pressure & Capacitive Silicon Barometer & Vaisala WXT520 \\
\hline $\begin{array}{l}\text { Ambient Temperature } \\
(1.07 \mathrm{~m}[3.5 \mathrm{ft}] \text { height })(1)\end{array}$ & $\begin{array}{l}\text { RTD Air Probe in an } \\
\text { Aspirated Radiation Shield }\end{array}$ & $\begin{array}{l}\text { R. M. Young 41342LC } \\
\text { in an } \\
\text { R. M. Young 43502-90 }\end{array}$ \\
\hline $\begin{array}{l}\text { Ambient Temperature } \\
(5.59 \mathrm{~m}[18.3 \mathrm{ft}] \text { height })(2)\end{array}$ & $\begin{array}{l}\text { Capacitive Ceramic } \\
\text { Thermometer }\end{array}$ & Vaisala WXT520 \\
\hline Current Signal & Shunt Resistor & Campbell Scientific CURS100 \\
\hline Diffuse Horizontal Irradiance (DHI) & $\begin{array}{l}\text { Black and White Thermopile } \\
\text { Pyranometer }\end{array}$ & Eppley 8-48 \\
\hline Digital Image (1) & PTZ Camera & Axis Q6032-E \\
\hline Digital Image (2) & Stationary Camera & Campbell Scientific CC5MPX \\
\hline Direct Normal Irradiance (DNI) & Thermopile Pyrheliometer & Kipp \& Zonen CHP 1 \\
\hline Global Horizontal Irradiance (GHI) (1) & Thermopile Pyranometer & Kipp \& Zonen CMP 21 \\
\hline Global Horizontal Irradiance (GHI) (2) & $\begin{array}{l}\text { Flat-Plate Silicon Irradiance } \\
\text { Sensor }\end{array}$ & IMT Solar Si-420TC \\
\hline Global Horizontal Irradiance (GHI) (3) & $\begin{array}{l}\text { Domed Diffused Silicon-Cell } \\
\text { Pyranometer }\end{array}$ & Apogee SP-230 \\
\hline Hail & Piezoelectric Sensor & Vaisala WXT520 \\
\hline Longwave Irradiance (incident and net) & Pyrgeometer & Eppley PIR \\
\hline
\end{tabular}




\begin{tabular}{|c|c|c|}
\hline Module Backsheet Surface Temperature (1) & RTD, 4-wire, class A, $100 \Omega$ & Omega SA1-RTD-4W-80 \\
\hline Module Backsheet Surface Temperature (2) & Thermocouple, Type T & Omega CO1-T-72 \\
\hline Plane-of-Array (POA) Irradiance & $\begin{array}{l}\text { Flat-Plate Silicon Irradiance } \\
\text { Sensor }\end{array}$ & IMT Solar Si-420TC \\
\hline Rain (1) & Piezoelectric Sensor & Vaisala WXT520 \\
\hline Rain (2) and Precipitation Liquid Content & $\begin{array}{l}\text { Heated Tipping Bucket Rain } \\
\text { Gauge }\end{array}$ & R. M. Young 52202 \\
\hline Reference Module (1) & PV Module & Powerlight PowerGuard* \\
\hline Reference Module (2) & PV Module & Sharp NU-U235F2 \\
\hline Reference Module (3) & PV Module & Sunpower SPR-320E-WHT-D \\
\hline $\begin{array}{l}\text { Reference Module I-V Curve and Maximum } \\
\text { Power Point }\end{array}$ & $\begin{array}{l}\text { I-V Curve Tracer with } \\
\text { Maximum Power Tracker and } \\
\text { Load }\end{array}$ & Daystar Multi-Tracer 5 \\
\hline Relative Humidity & $\begin{array}{l}\text { Capacitive Thin Film Polymer } \\
\text { Hygrometer }\end{array}$ & Vaisala WXT520 \\
\hline RTD Current & Shunt Resistor & $\begin{array}{l}\text { Campbell Scientific } \\
\text { 4WPB100 }\end{array}$ \\
\hline Snow Depth & Sonic Ranging Sensor & Campbell Scientific SR50A \\
\hline Spectral Irradiance (1) & Spectroradiometer & EKO MS-710 \\
\hline Spectral Irradiance (2) & Spectroradiometer & EKO MS-712 \\
\hline Thermocouple Reference Temperature & UTR with RTD & Campbell Scientific AM25T \\
\hline UV Total Irradiance & UV Radiometer & Eppley TUVR \\
\hline UV-A Irradiance & UV Radiometer & EKO MS-210A \\
\hline UV-B Irradiance & UV Radiometer & EKO MS-212W \\
\hline Voltage Signal & Data Logger & $\begin{array}{l}\text { Campbell Scientific } \\
\text { CR1000-ST }\end{array}$ \\
\hline $\begin{array}{l}\text { Wind Speed and Direction } \\
(5.72 \mathrm{~m}[18.8 \mathrm{ft}] \text { height })(1)\end{array}$ & Ultrasonic Wind Sensor & Vaisala WXT520 \\
\hline $\begin{array}{l}\text { Wind Speed and Direction } \\
(2.51 \mathrm{~m}[8.3 \mathrm{ft}] \text { height })(2)\end{array}$ & Ultrasonic Wind Sensor & Vaisala WS425 \\
\hline
\end{tabular}

\footnotetext{
* The module itself without the mounting is a Siemens SP150-CPL
}

Unless noted otherwise, the instruments and sensors are wired directly to one of the data loggers, multiplexers, or serial communication modules using UV and moisture protected cables run through metal dedicated data conduit, separating them from power conductors that may generate high EMI. The cables enter the conduit through cable glands at pull boxes or conduit access ports. The instruments and sensors are wired using twisted-pair or, if carrying multiple sensor signals and/or the instruments power, twisted multi-conductor cable. The cables are shielded and grounded at one end on the data logger side to reduce and allow the EMI to be later rejected when differentially measured, which is especially important for the $\sim 10 \mu \mathrm{V}$ resolution analog voltage output of the thermopile radiometers. 


\subsection{Global Shortwave Irradiance}

\subsubsection{Sensors}

The global horizontal irradiance (GHI) is measured using two redundant Kipp \& Zonen CMP 21 thermopile pyranometers, an IMT Solar Si-420TC flat-plate silicon irradiance sensor, and an Apogee SP-230 domed diffused silicon-cell pyranometer. The plane-of-array (POA) irradiance of each of the installed reference modules are also measured using the same IMT Solar flat-plate irradiance sensor. The thermopile pyranometers are all-black sensor, secondary-standard pyranometers. The flat-plate silicon sensors are a shunted monocrystalline silicon cell under a thin glass cover with a cell temperature-compensated output signal. The domed diffused silicon-cell pyranometer functions very similarly to the flat-plate irradiance sensors, but has a dome-shaped diffuser over the cell that minimizes reflective losses.

Thermopile pyranometers were installed to most accurately measure the GHI and to be consistent with the traditional method of measuring the GHI, allowing better comparisons to be made with other measurements. These specific pyranometers were also chosen because they have an integrated thermistor measuring the case temperature, which can be used to correct for the temperature dependency of the instrument's responsivity to obtain more accurate irradiance measurements. Two redundant pyranometers are installed, connected to separate data loggers, to maximize data availability and to provide comparative checks of the measurements. Flat-plate silicon irradiance sensors were installed to capture the irradiance under fast changing conditions at nearly instantaneous speeds, unlike the pyranometers which have multiple-second response times. The flat-plate irradiance sensors, when mounted in the modules' respective planes, also better approximate the modules' effective irradiances, or that absorbed by the PV cells, because they have similar reflective properties due to the flat glass covers and similar spectral responses since both utilize monocrystalline silicon cells. Pyranometers, in comparison, measure the incident irradiance. The domed diffused silicon-cell pyranometer was installed because, like the flat-plate irradiance sensors, it captures fast changing irradiance, but unlike those sensors it measures the incident, rather than the absorbed, irradiance.

These types of instruments were also chosen because they are either the same, or functionally the same sensors installed at the campus PV arrays, which will allow better comparisons to be made with the latter measurements. The pyranometers at the arrays are also all-black sensor, secondary standard pyranometers, the flat-plate irradiance sensors are the exact same, and the silicon pyranometers are also the exact same except that the one at the weather station has an integrated heater to prevent snow and ice from occluding the sensor.

\subsubsection{Calibrations}

All thermopile pyranometers are replaced every year with ones that have been newly calibrated at the National Renewable Energy Laboratory (NREL) according to their Broadband Outdoor Radiometer Calibration (BORCAL) procedure [10]. This calibration provides net-IR corrected responsivities $\left(\mu \mathrm{V} /\left(\mathrm{W} \cdot \mathrm{m}^{-2}\right)\right)$ at every $2^{\circ}$ in the measured solar zenith angle range. The silicon sensors were calibrated in a solar simulator at the factory and verified to be within specifications. The flat-plate irradiance sensors have a stated yearly drift of $0.5 \%$, and the domed diffused silicon pyranometers have a yearly drift of less than $2 \%$.

\subsubsection{Locations and Orientations}

The instruments measuring the GHI are located on the east of the two tables, as shown in Figure 3-1. As described in section 2.1.1 Facilities, all radiometers on the east table are aligned vertically to normalize the heights of their sensor elements to within $1 \mathrm{~cm}(0.4$ in.) to minimize the instruments' mutual shading and sky occlusion. All pyranometers are oriented with their connectors facing away from the equator (north), as is the standard practice and also how they were oriented during calibration. The flat-plate silicon irradiance sensor is oriented with its connector facing west to replicate the landscape orientation of these sensors in the arrays. 


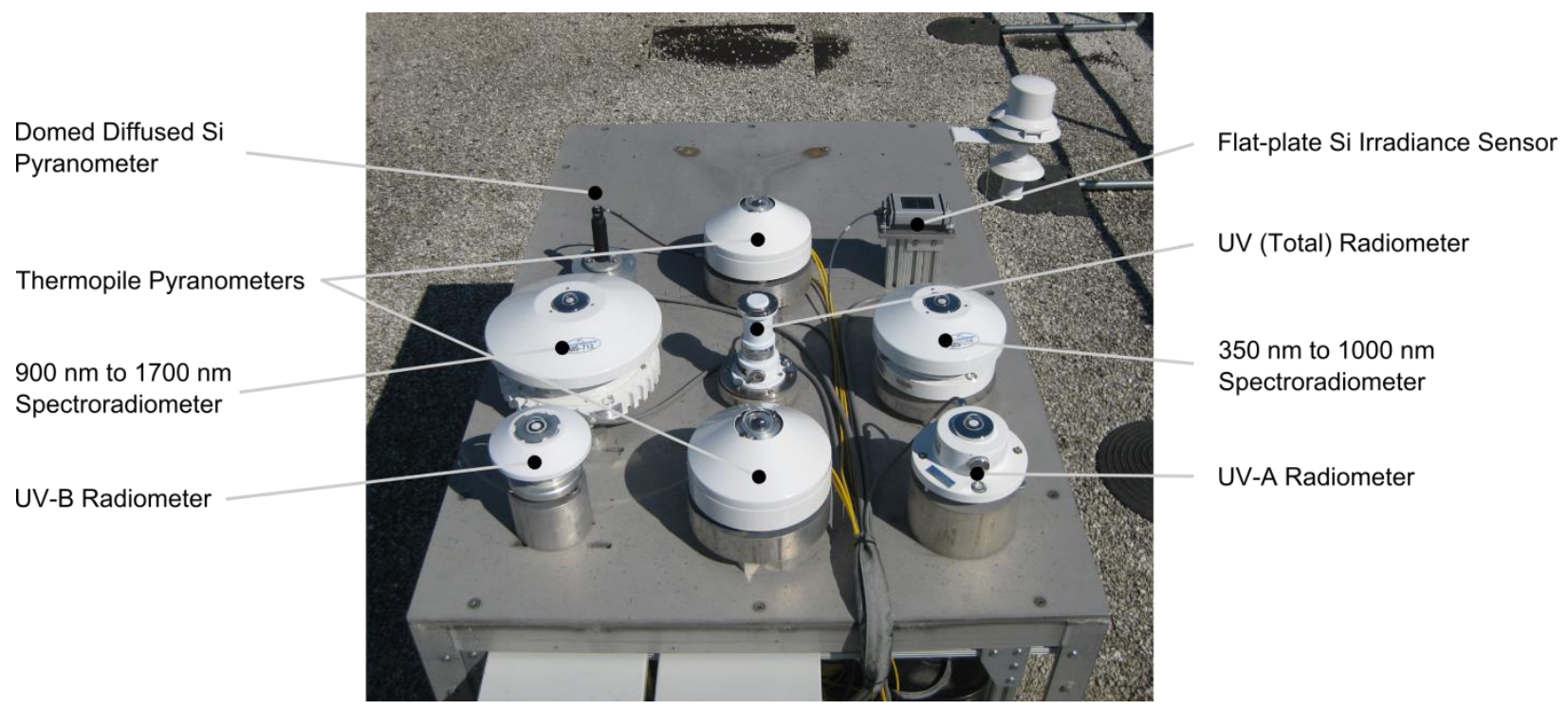

Figure 3-1 The east table, looking north, with the GHI measuring pyranometers and silicon irradiance sensor mounted on it. Also shown are the spectroradiometers, UV radiometers, and the ambient temperature sensor (upper right).

The flat-plate silicon irradiance sensors measuring the POA irradiances are located in the respective module planes, next to a north, high corner of the module, as shown in Figure 3-2, except for the sensor for the horizontal module, which is the one located on the east table. These sensors are oriented with their connectors facing toward the top of the module, which is north except for those for the two east and west facing modules, with their connectors facing west and east, respectively.



Figure 3-2 Flat-plate silicon irradiance sensors measuring the POA irradiances on their respective reference modules

\subsubsection{Mounting and Alignment}

The two Kipp \& Zonen CMP 21 thermopile pyranometers are mounted in Kipp \& Zonen CVF 3 ventilators. These ventilators blow heated air up and over the pyranometers, which reduces the dirt, dew, frost, and snow buildup on 
the glass domes. This airflow also reduces the 'Zero Offset Type A' bias uncertainty of the irradiance measurement by reducing the temperature difference between the body and glass dome of the instrument. The domed diffused silicon-cell pyranometer is mounted on an Apogee AL-100 leveling plate, and the flat-plate silicon irradiance sensor is mounted using a custom-made mount. The flat-plate silicon sensors measuring the POA irradiances are mounted next to their respective reference modules using Campbell Scientific CM245 Adjustable-Angle Mounting Stands.

The pyranometers are leveled using their integrated bubble levels, ensuring that the bubble is in the middle of the center circle, with the bubble anywhere in the circle corresponding to a leveling accuracy of approximately $\pm 0.1^{\circ}$ for the Kipp \& Zonen CMP 21's and $\pm 0.4^{\circ}$ for the Apogee SP-230 on its AL-100 leveling plate. The GHI and POA flatplate irradiance sensors are aligned to horizontal and the module tilts, respectively, using a Mitutoyo Pro 360 inclinometer to a reading within $\pm 0.1^{\circ}$.

\subsubsection{Wiring}

The GHI measuring instruments are wired as described in section 3.1, except for the flat-plate irradiance sensors, which are similarly wired using shielded twisted three-wire cable. These silicon sensors communicate over an unpowered $4 \mathrm{~mA}$ to $20 \mathrm{~mA}$ current loop, which has a low sensitivity to electrical noise, and runs on one pair, with the third wire supplying power to the temperature compensation and loop transmitter circuits.

\subsection{Direct and Diffuse Shortwave Irradiance}

\subsubsection{Sensors}

The direct normal irradiance (DNI) is measured using two redundant Kipp \& Zonen CHP 1 pyrheliometers. The diffuse horizontal irradiance (DHI) is measured using two redundant Eppley 8-48 pyranometers. The former are first class thermopile pyrheliometers and the latter are black and white thermopile pyranometers.

These two types of instruments were installed to most accurately measure the DNI and DHI and to be consistent with the traditional methods of measuring these values, therefore allowing direct comparisons with other measurements. These specific pyrheliometers were also chosen because they have integrated temperature sensors measuring the case temperature, which can be used to correct for the temperature dependency of the instrument's responsivity to obtain more accurate irradiance measurements. Thermopile pyranometers with black and white sensors were chosen instead of those with all-black sensors because they have negligible Zero Offset Type A biases, which are significant for all-black thermopile pyranometers when shaded. The negligible bias of the black and white pyranometers is due to their hot and cold junctions being in the same thermal environment. Like the GHI measuring thermopile pyranometers, redundant pyrheliometers and diffuse-measuring pyranometers are installed, connected to separate data loggers, to maximum data availability and to provide comparative checks of the measurements.

\subsubsection{Calibrations}

Like the GHI measuring pyranometers, the pyrheliometers are replaced every year with ones that have been newly calibrated at NREL according to their BORCAL procedure [10]. This calibration also provides net-IR corrected responsivities $\left(\mu \mathrm{V} /\left(\mathrm{W} \cdot \mathrm{m}^{-2}\right)\right)$ for pyrheliometers at every $2^{\circ}$ in the measured solar zenith angle range. The diffusemeasuring pyranometers are replaced every year with ones that have been newly calibrated by the manufacturer in an integrating sphere.

\subsubsection{Locations and Orientations}

The pyrheliometers and diffuse-measuring pyranometers are both located on the same Kipp \& Zonen 2AP Gear Drive with Sun Sensor solar tracker, as shown in Figure 3-3 and described in section 2.1.1 Facilities. The pyranometers are oriented with their connectors facing away from the sun. 


\subsubsection{Mounting and Alignment}

The pyrheliometers are mounted on the tracker's side mounting plates and the diffuse-measuring pyranometers are mounted on the tracker's rear mounting plate in Eppley VEN ventilators that blow unheated air up and over the pyranometers, which reduces the dirt, dew, frost, and snow buildup on the glass domes. These ventilators have direct current (DC) instead of alternating current (AC) fans to minimize any EMI induced in the pyranometer sensor cables.

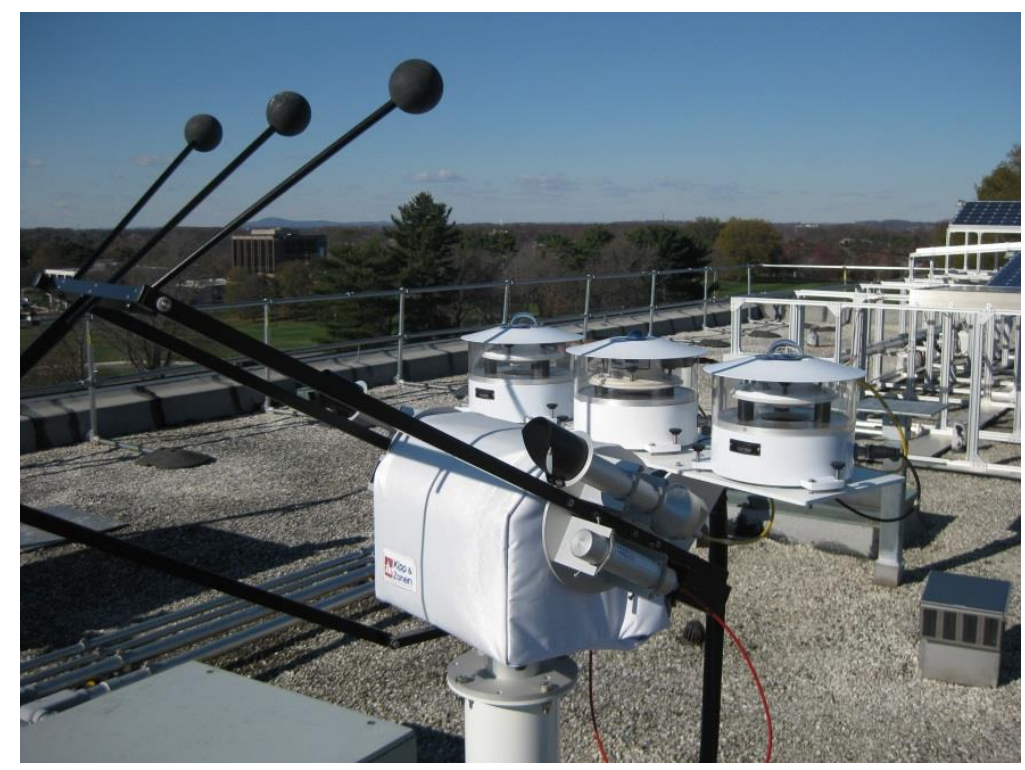

Figure 3-3 The pyrheliometers mounted on the solar tracker above the sun sensor and below the horizontal diffuse-measuring pyranometers (left and right) and IR measuring pyrgeometer (center). The black balls shade the three horizontal instruments.

The tracker is leveled using its integrated bubble level, ensuring that the bubble is in the middle of the center circle. The pyrheliometers are aligned to each other and to the sun sensor according to the tracker instructions. The diffusemeasuring pyranometers are leveled using their integrated bubble levels, also ensuring that the bubble is in the middle of the center circle, with the bubble anywhere in the circle corresponding to a leveling accuracy of approximately $\pm 0.2^{\circ}$. The shading balls are positioned so the pyranometers' sensor elements are in the center of their shadows at solar noon, when the shadows are smallest. The solar tracker's sun tracking accuracy is $<0.05^{\circ}$, which is within the required accuracy of $0.75^{\circ}$ for getting a full response from these model pyrheliometers [11] and well within that needed to keep the shading balls centered over the diffuse-measuring pyranometers.

\subsection{Longwave Irradiance}

The incident and net horizontal longwave irradiance is measured using an Eppley Precision Infrared Radiometer (PIR). This pyrgeometer was chosen because it has historically been one of the most popular in climate research and has class-leading specifications. The case temperature is measured using an integrated thermistor to calculate the instrument's emitted IR and subsequently the incident IR from the net IR measurement. The dome temperature is not measured.

The pyrgeometer is replaced every 18 months with one that has been newly calibrated outdoors at NREL. The pyrgeometer is mounted on the solar tracker between the diffuse pyranometers in an Eppley VEN ventilator, as shown in Figure 3-3, oriented with the connector facing away from the sun. Like those for the diffuse pyranometers, this ventilator blows unheated air up and over the pyrgeometer to reduce the dirt, dew, frost, and snow buildup on the instrument dome. This ventilator also has a DC fan to minimize any EMI induced in the sensor cable. 
The pyrgeometer is leveled using its integrated bubble level to an accuracy of approximately $\pm 0.2^{\circ}$ and is shaded in the same manner as the diffuse pyranometers. Shading the pyrgeometer reduces heating of its dome and the correction needed for the associated signal bias.

\subsection{UV Irradiance}

The UV irradiance is measured using an EKO MS-210A, an EKO MS-212W, and an Eppley TUVR. The EKO MS210A measures the UV-A irradiance in the spectral range of $315 \mathrm{~nm}$ to $400 \mathrm{~nm}$, the EKO MS-212W measures the UV-B irradiance in the spectral range of $280 \mathrm{~nm}$ to $315 \mathrm{~nm}$, and the Eppley TUVR measures the total UV irradiance in the spectral range of $295 \mathrm{~nm}$ to $385 \mathrm{~nm}$. The total UV irradiance measurement is mostly redundant, which helps to maximize data availability and provide comparative checks with the other UV measurements. The UV-A and UVB radiometers are calibrated outdoors every 18 months by a commercial testing laboratory; the UV total radiometer is replaced every 18 months with one that has been newly calibrated by the manufacturer. The UV radiometers are located on the east table alongside the other stationary radiometers and oriented with their connectors facing away from the equator (north), as shown in Figure 3-1. They are mounted horizontally and are leveled using their respective integrated bubble levels, ensuring that the bubble is in the middle of the center circle, with the bubble anywhere in the circle corresponding to an unspecified accuracy for the UV-A and UV-B radiometers and to an accuracy of approximately $\pm 0.2^{\circ}$ for the UV total radiometer. The radiometers are wired to converter boxes in an indoor enclosure, which power the radiometers and output analog signals proportional to the measured irradiances.

\subsection{Spectral Irradiance}

The spectral irradiance is measured using an EKO MS-710 spectroradiometer and an EKO MS-712 spectroradiometer. The MS-710 measures in the nominal spectral range of $350 \mathrm{~nm}$ to $1000 \mathrm{~nm}$ in $0.7 \mathrm{~nm}$ to $0.8 \mathrm{~nm}$ increments and the MS-712 measures in the nominal spectral range of $900 \mathrm{~nm}$ to $1700 \mathrm{~nm}$ in $1.9 \mathrm{~nm}$ to $1.4 \mathrm{~nm}$ increments. These spectroradiometers were chosen because they have class-leading specifications for continuous outdoor measuring instruments.

The spectroradiometers are calibrated every 18 months indoors in a NIST laboratory designed for such calibrations. The calibrations are performed using the NIST-calibrated spectral irradiance standard 1000 W FEL lamp [12], with the lamp optically aligned $50 \mathrm{~cm}$ from the instruments' diffuser. The spectral irradiance responsivities of the spectroradiometers are calibrated using the known spectral irradiance of the lamp and are stored as calibration functions in the instruments.

The spectroradiometers are located on the east table alongside the other stationary radiometers and oriented with their connectors facing away from the equator (north), as shown in Figure 3-1. They are mounted horizontally and are leveled using their respective integrated bubble levels, ensuring that the bubble is in the middle of the center circle, with the bubble level accuracies unspecified. The spectroradiometers are wired to indoor converter boxes, which power the spectroradiometers and relay the measurements using RS-232 serial communications connections.

\subsection{Ambient Temperature}

\subsubsection{Sensors}

The outdoor ambient air temperature is measured using an R. M. Young 41342LC $1000 \Omega$ platinum resistance temperature detector (RTD) probe and transducer in an R. M. Young 43502-90 aspirated radiation shield. The radiation shield is used to shield the temperature probes from radiative heat transfer from the sun and surroundings, which would affect the temperature of the probe, while still allowing ambient airflow around the probe. An aspirated, or fan ventilated, radiation shield was used instead of a passively-ventilated shield to minimize stagnant air around the probe, resulting in more accurate and responsive measurements. The backup power system also has the capacity for an aspirated shield, unlike the smaller systems at the campus PV DASs where fanless passivelyventilated shields are used. 
The outdoor ambient air temperature is also measured by a Vaisala WXT520 weather transmitter. This instrument has a capacitive ceramic thermometer inside of multi-plate passively ventilated radiation shield. The weather transmitter is configured to sample temperature readings at $4 \mathrm{~Hz}$ and average every $1 \mathrm{~s}$. It communicates over one wire pair using an RS485 serial ASCII protocol at 19200 bits per second (bps).

\subsubsection{Calibrations}

Both sets of ambient temperature sensors were calibrated at the factory and verified to be within specifications, and their yearly drift is unspecified.

\subsubsection{Locations and Orientations}

The aspirated shield and sensor is located near the stationary radiometers on the east table, mounted in a vertical orientation northeast of the radiometers in a location that does not shade the radiometers, is not in stagnant air, and is not near potentially heat-releasing sources like roof vents, as shown in Figure 3-4.

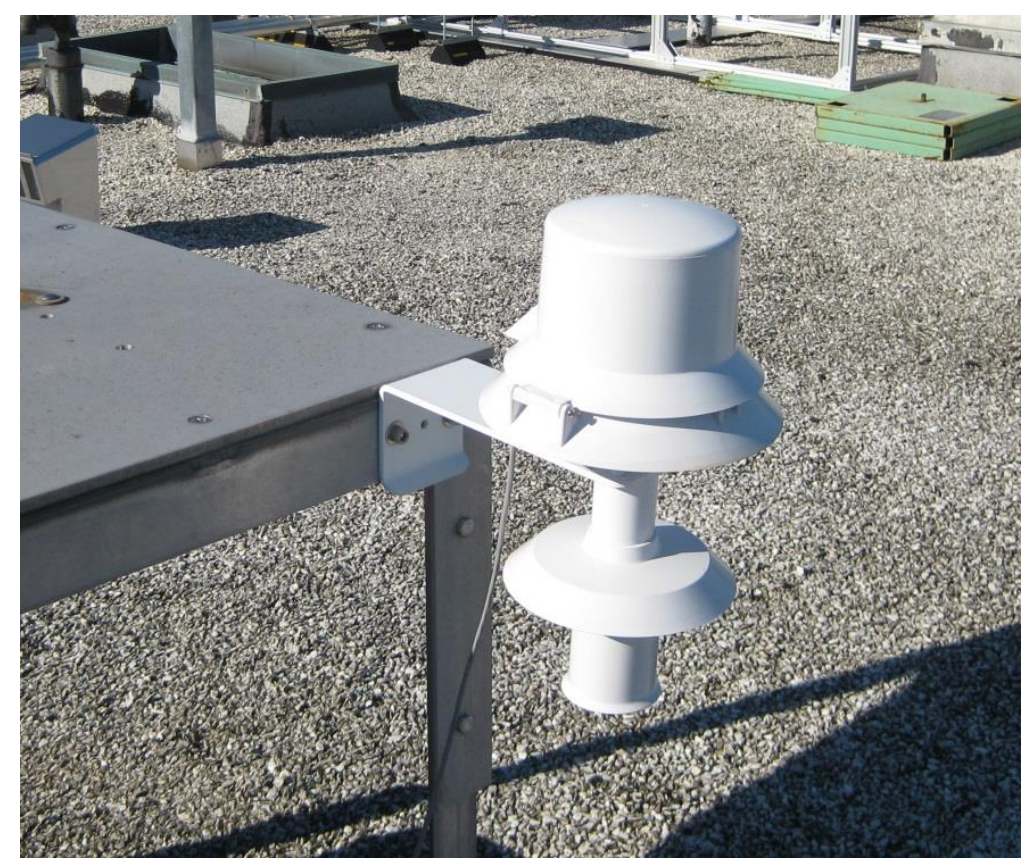

Figure 3-4 The temperature sensing probe in the aspirated radiation shield used to measure the outdoor ambient air temperature

The weather transmitter is located $5.59 \mathrm{~m}(18.3 \mathrm{ft})$ above the roof in an upright vertical orientation on the mast in the farthest north, east-west center of the roof, as shown in Figure 3-5. This high location is intended to measure the temperature of the air that is less affected by any heat generating roof elements, while its north-center location minimizes its shading on the other roof instruments and modules. The weather transmitter is just below the lightning rod on the mast so a Vaisala WSP150 surge protector, designed for this type of application, was installed near it on the mast and in-line with the power and data cable to suppress power surges caused by nearby lightning. The specific locations of both sets of sensors are shown in the diagram in Figure 2-1. 




Figure 3-5 The weather transmitter near the top of the instrument mast

\subsubsection{Wiring}

The weather transmitter is wired to the surge protector, and this surge protector and the aspirated temperature sensor are wired directly to a data logger serial communication module and multiplexer, respectively. The aspirated temperature sensor communicates via a transducer over a powered $4 \mathrm{~mA}$ to $20 \mathrm{~mA}$ current loop, which has a low sensitivity to electrical noise and also supplies power to the sensor.

The weather transmitter communicates over one wire pair, with power for the sensors and the heater on separate wire pairs. To reduce power consumption, termination resistors are not wired in parallel at the ends of the RS485 communication wires to reduce signal reflections because they are not needed, as the cable lengths are less than $600 \mathrm{~m}(2000 \mathrm{ft})$ and the data rates are relatively low (19200 bps). The surge protector for this sensor is grounded to the building's lighting ground via the mast and lightning wire.

\subsection{Wind}

\subsubsection{Sensors}

The horizontal wind speed and direction are measured using a Vaisala WXT520 weather transmitter having a heated ultrasonic wind sensor and a Vaisala WS425 ultrasonic wind sensor. Ultrasonic sensors were chosen instead of traditional vane and cup or windmill anemometers because they have a smaller physical profile, are easily heated and kept free of snow and ice, have no moving parts and therefore a higher reliability, and have a higher sensitivity because of the faster response time and virtually zero starting threshold (even very low wind speeds are detected).

The weather transmitter is configured to sample wind readings at $4 \mathrm{~Hz}$ and average them every $1 \mathrm{~s}$, and to perform maximum and minimum calculations instead of gust and lull. The weather transmitter controls its level of heating as a function of the ambient and its internal temperatures. It communicates over one wire pair using an RS485 serial ASCII protocol at 19200 bps.

The other ultrasonic wind sensor is configured to sample readings at $1 \mathrm{~Hz}$ and perform no averaging. This sensor is not heated and communicates over three wires using two analog voltage signals. The signals are $0 \mathrm{~V}$ to $1 \mathrm{~V}$ and $0 \mathrm{~V}$ to the supplied reference voltage, proportional to the wind speed and direction, respectively. The reference voltage is approximately $1.5 \mathrm{~V}$, which is supplied by the datalogger via a custom voltage divider connected to one of the datalogger's power output terminals. The reference voltage is measured after each wind direction measurement. 


\subsubsection{Calibrations}

The sensors were calibrated at the factory and verified to be within specifications, and they have an unspecified yearly drift.

\subsubsection{Locations and Orientation}

The weather transmitter is located on a mast crossarm in an upright vertical orientation, with its wind transducers $5.72 \mathrm{~m}(18.8 \mathrm{ft})$ above the roof and $36 \mathrm{~cm}(14 \mathrm{in}$.) west of the mast, in the farthest north, east-west center of the roof, as shown in Figure 3-5. This high location aims to measure close to the free-stream wind, while its north-center location minimizes its shading on the other roof instruments and modules. The wind at this height, however, is most likely still affected by the building. The other ultrasonic wind sensor is located on a lower mast crossarm in an upright vertical orientation, with its transducers $2.51 \mathrm{~m}(8.3 \mathrm{ft})$ above the roof and $84 \mathrm{~cm}(33 \mathrm{in}$.) west of the mast, as shown in Figure 3-6. The transducers are positioned $33 \mathrm{~cm}(13 \mathrm{in}$.$) above the top of the highest, farthest north$ reference modules and $90 \mathrm{~cm}$ (35.5 in.) behind them. This location aims to measure the wind that is near to but out of the immediate boundary layer of the modules while minimally shading the modules.



Figure 3-6 The lower ultrasonic wind sensor (left) and heated tipping bucket rain gauge (right) on the lower instrument mast crossarm

\subsubsection{Mounting and Alignment}

The wind sensors are mounted on top of vertical poles, aligned to true north using visual references and checked with a compass (adjusted for the local magnetic declination). Metal spikes designed for this specific sensor are installed on top of the weather transmitter to deter birds from perching on it and affecting the readings. The lower ultrasonic wind sensor has no surge protector or metal spikes installed.

\subsubsection{Wiring}

The wiring of the weather transmitter is described in section 3.7.4. The lower ultrasonic wind sensor is wired directly to the data logger and communicates over two wires and a common ground, with power supplied using a separate wire pair.

\subsection{Ambient Pressure and Humidity}

The ambient pressure and relative humidity are also measured using the aforementioned Vaisala WXT520 weather transmitter. The capacitive silicon pressure and capacitive thin film polymer humidity sensors are located in the 
instrument's passively-ventilated radiation shield. The sensors are calibrated at the factory and verified to be within specifications, and have an unspecified yearly drift; they are replaced every 18 months. The sensors are located $5.59 \mathrm{~m}(18.3 \mathrm{ft})$ above the roof in an upright vertical orientation on the mast in the farthest north, east-west center of the roof, as shown in Figure 3-5. This high location aims to measure the humidity of the air that is less affected by any roof vents, while its north-center location minimizes its shading on the other roof instruments and modules. The weather transmitter is configured to sample ambient pressure and humidity readings at $4 \mathrm{~Hz}$ and average them every $1 \mathrm{~s}$. The wiring of the weather transmitter is described in section 3.7.4.

\subsection{Precipitation}

\subsubsection{Liquid}

\subsubsection{Sensors}

Liquid precipitation is measured using an R. M. Young 52202 rain gauge and a Vaisala WXT520 weather transmitter. The R. M. Young 52202 is a tipping bucket rain gauge that is heated to also measure the liquid content of snow, sleet, hail, and freezing rain. It has a $200 \mathrm{~cm}^{2}\left(31 \mathrm{in}^{2}\right)$ catchment area, or $16 \mathrm{~cm}(6.3 \mathrm{in}$.) diameter, with a $0.1 \mathrm{~mm}(4 \mathrm{mil})$ resolution. The weather transmitter has a horizontal steel surface on top of the instrument that is connected to a piezoelectric sensor that measures the frequency and magnitude of raindrop impacts. The instrument correlates the magnitude of these impacts to the volume of the rain drops. The weather transmitter is configured to record accumulated rainfall depth.

The tipping bucket rain gauge was chosen because it is a traditional means of measuring rainfall, while the piezoelectric sensor provides a higher resolution and faster response time than the tipping bucket gauge.

\subsubsection{Calibrations}

Both instruments were calibrated at the factory and verified to be within specifications, and they have an unspecified yearly drift.

\subsubsection{Locations and Orientations}

The tipping bucket gauge is located on a mast crossarm, with its catchment opening $2.31 \mathrm{~m}(7.6 \mathrm{ft})$ above the roof, $84 \mathrm{~cm}$ (33 in.) east of the mast and $90 \mathrm{~cm}$ (35.5 in.) north of the northern-most reference module, as shown in Figure 3-6. The piezoelectric sensor is located $5.69 \mathrm{~m}(18.7 \mathrm{ft})$ above the roof on a mast crossarm, $36 \mathrm{~cm}(14 \mathrm{in}$.) west of the mast. Both are mounted on top of vertical poles and aligned vertically, and both have spikes installed on top to deter birds from perching on and fouling them and affecting their readings.

\subsubsection{Wiring}

The tipping bucket rain gauge and weather transmitter are wired as described in section 3.1 and section 3.7.4, respectively.

\subsubsection{Solid}

\subsubsection{Sensors}

Snow depth is measured using a Campbell Scientific SR50A sonic ranging sensor, hail is measured using a Vaisala WXT520 weather transmitter, and the liquid content of all solid precipitation is measured using the R. M. Young 52202 heated rain gauge described in section 3.10.1. The snow sensor measures the distance from the sensor to the roof with the snow depth calculated as the difference between the height of the sensor and the measured distance. The measured ambient temperature is required to correct the readings for speed-of-sound variations. The hail sensor on the weather transmitter is the same sensor that measures the rain; it is a horizontal steel surface connected to a piezoelectric sensor that measures the frequency of impacts. It distinguishes between hail and rain impacts, but only counts the frequency of the hail impacts. The area of this steel surface is $60 \mathrm{~cm}^{2}\left(9.3 \mathrm{in}^{2}\right)$. 
The snow sensor is configured to sample readings every 30 seconds. It uses the ambient temperature measured by the closer aspirated temperature sensor to correct the readings. The weather transmitter is configured to record the accumulated number of hail impacts.

\subsubsection{Calibrations}

The sensors were calibrated at the factory and verified to be within specifications, and they have unspecified yearly drifts.

\subsubsection{Locations and Orientations}

The snow sensor is located $124 \mathrm{~cm}$ (49 in.) north of the west table on a horizontal crossarm, $121.6 \mathrm{~cm}$ (47.87 in.) above a $71 \mathrm{~cm} \times 71 \mathrm{~cm}(28$ in. x 28 in.) aluminum plate resting on the roof, as shown in Figure 3-7. This plate provides a uniform target that allows consistent readings when there is little snow.



Figure 3-7 The snow sensor that measures snow depth, positioned directly above a square flat metal plate

The piezoelectric sensor measuring the hail, which is part of the weather transmitter, is located $5.69 \mathrm{~m} \mathrm{(18.7 \textrm {ft } )}$ above the roof on a mast crossarm, $36 \mathrm{~cm}$ (14 in.) west of the mast, as shown in Figure 3-5.

The snow sensor is aligned normal (plumb) to the center of the aluminum plate and the hail sensor is aligned vertically. The hail sensor has spikes installed on top to deter birds from perching on and fouling the sensor and affecting its readings.

\subsubsection{Wiring}

The snow sensor and weather transmitter are wired as described in section 3.1 and section 3.7.4, respectively.

\subsection{Reference Modules}

Reference PV modules, one for each module orientation in the campus PV arrays, are installed in the same orientations at the weather station, as summarized in Table 3-2. Manufacturer data sheets are provided in Appendix B. These reference modules provide baseline measurements without the significant wiring, mismatch, soiling, snow, shading, and other losses of the modules in the arrays. These reference modules also provide data on their aging, and 
their true average cell temperature and absorbed/effective irradiance from their measured I-V curves, which can be correlated with the measured backsheet surface temperature and POA irradiance, respectively.

Table 3-2 Summary of Reference Modules

\begin{tabular}{|c|c|c|c|c|c|}
\hline Respective Array & Canopy & Ground & Roof Tilted & $\begin{array}{c}\text { Roof } \\
\text { Horizontal }\end{array}$ & NZERTF \\
\hline Module Manufacturer & & Sharp & & Powerlight ${ }^{*}$ & Sunpower \\
\hline Module Model & & NU-U235F2 & & PowerGuard* & $\begin{array}{l}\text { SPR-320E- } \\
\text { WHT-D }\end{array}$ \\
\hline Module Technology & mono & $\mathrm{c}-\mathrm{Si}-$ front & ontact & $\begin{array}{l}\text { mono c-si - } \\
\text { front contact }\end{array}$ & $\begin{array}{l}\text { mono c-si - } \\
\text { back contact }\end{array}$ \\
\hline Module Rated Power [W] & & 235 & & 150 & 320 \\
\hline Location & $\begin{array}{c}\text { Middle } \\
\text { East / West }\end{array}$ & NW & $\begin{array}{l}\text { Second } \\
\text { from South }\end{array}$ & South & $\mathrm{NE}$ \\
\hline Tilt $\left[{ }^{\circ}\right]$ & $5 / 5$ & 20 & 10 & 0 & 18.4 \\
\hline Azimuth [ ${ }^{\circ} \mathrm{CW}$ from $\left.\mathrm{N}.\right]$ & $90 / 270$ & 180 & 180 & 180 & 180 \\
\hline Flashing & No & No & Yes & Yes & Yes \\
\hline One-way Wire Length [m] & $105 / 105$ & 115 & 105 & 90 & 130 \\
\hline
\end{tabular}

* The module itself without the mounting is a Siemens SP150-CPL

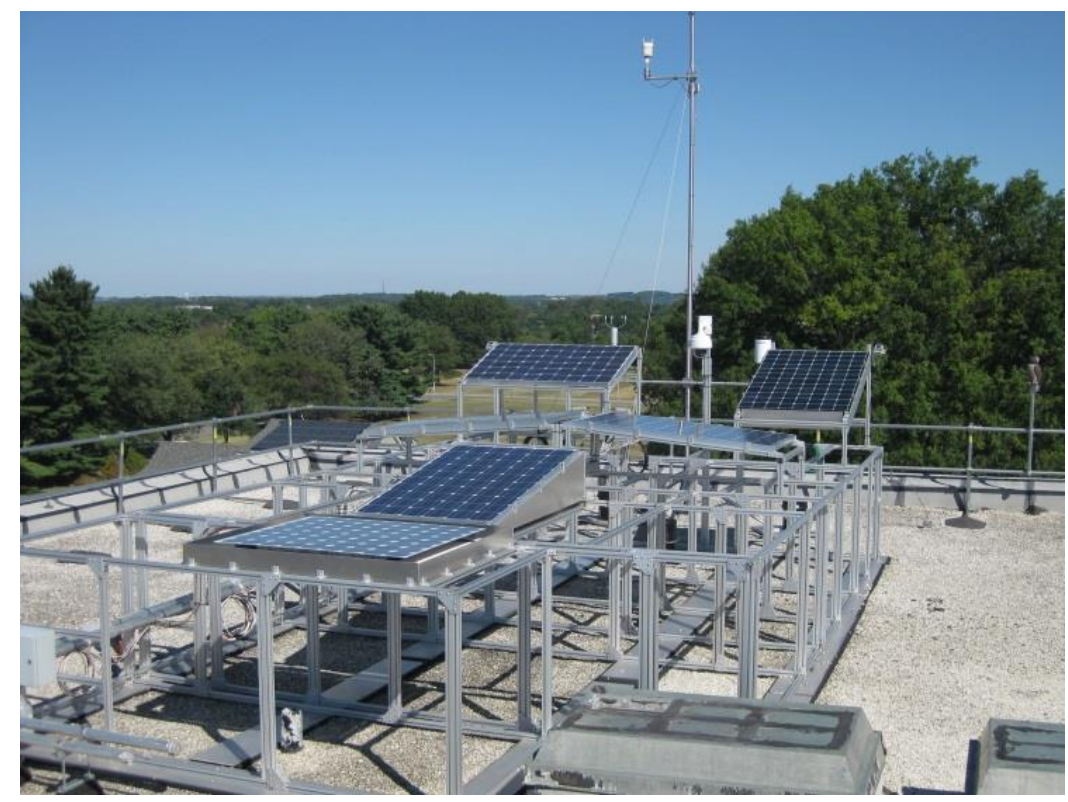

Figure 3-8 The reference modules installed at the weather station

These reference modules (except the one for the Roof Horizontal array) were previously unexposed and are from the same production batches as those installed at each array. As previously described, the modules are arranged according to a CAD model, which calculated less than 45 minutes of any mutual or external shading on the modules at sunrise and sunset on the summer solstice and less than 5 minutes on the winter solstice, the two extremes of the year. The modules are aligned to their respective tilts using a Mitutoyo Pro 360 inclinometer to a reading within 
$\pm 0.2^{\circ}$, and are aligned to their respective azimuths using visual references and checked with a compass (adjusted for the local magnetic declination).

Sheet metal flashing is installed around the modules for the Roof Horizontal, Roof Tilted, and NZERTF arrays to simulate the effect of the respective installations on the module temperatures; the modules in the Canopy and Ground Arrays have open air circulation on their back sides and therefore have no flashing installed around their reference modules.

The POA irradiance on each module is measured using flat-plate silicon irradiance sensors, as described in section 3.2, and the backsheet surface temperatures of each module are measured at multiple locations using RTDs and thermocouples, as described in section 3.12. The modules are wired directly to an indoor I-V curve tracer with maximum power tracker and load using 10 AWG $\left(5.26 \mathrm{~mm}^{2}\right) \mathrm{UV}$ and moisture protected PV cable run through metal dedicated conduit.

\subsection{Module Temperature}

\subsubsection{Sensors}

The reference modules' backsheet surface temperatures are measured using Omega SA1-RTD-4W-80 RTDs and Omega CO1-T-72 thermocouples. The RTD is an exposed, thin-film, four-wire, class "A", $100 \Omega$ platinum RTD with an $\alpha=0.00385$. The sensing element is flat, with only a thin ceramic base material covering the resistive element, thereby reducing the thermal gradient in the sensor, bringing it closer to the module surface temperature. The RTD has a relatively small sensing area of $2 \mathrm{~mm} \times 2.2 \mathrm{~mm}(0.08$ in. $x 0.09$ in.) that results in faster response times due to the smaller thermal mass. The RTD has a large $19 \mathrm{~mm}$ x $26 \mathrm{~mm}$ ( $0.75 \mathrm{in}$ x $1.0 \mathrm{in}$.) adhesive backing to the sensing element, which provides secure mounting to the module. A four-wire RTD was chosen instead of a two or three-wire RTD because the long cable leads, the large changes in temperature and subsequent resistance of the sensing element, and using a static, unbalanced resistance bridge would have resulted in significant measurement errors.

The Omega CO1-T-72 thermocouple is an ungrounded, flat, low mass, type T, ANSI "Special Limits of Error" grade foil sensor. This temperature sensor is also flat to reduce the thermal gradient in the sensor and has a relatively small sensing area that results in a fast response time. The thermocouple sensing element is encapsulated in a $10 \mathrm{~mm}$ x $20 \mathrm{~mm}$ (0.4 in. x $0.8 \mathrm{in}$.) polymer laminate, which allows secure mounting to the module. A type T thermocouple was chosen because it is the most accurate in this application's measurement range.

The specific RTD and thermocouple models were originally chosen and installed on the modules in the arrays. Thermocouples were installed at the Roof Horizontal and NZERTF arrays, while RTDs were installed at the Canopy, Ground, and Roof Tilted arrays. The thermocouples were installed at the former arrays to more easily integrate with the existing data acquisition systems, while RTDs were installed at the latter arrays because they are the most stable and accurate temperature sensing technology [13]. RTDs also do not require a temperature reference unlike thermocouples, which for the higher accuracy and many channel units can be rather large, and in the case of ice point references require significant amounts of power. There is sufficient backup power and space at the former arrays for accurate temperature references but not at the locations of the latter arrays. RTDs do, however, need excitation, which requires a current source, increases the sampling time, and causes self-heating of the resistance sensor that affects the measurement. These issues were addressed and minimized, as later described in the Data Acquisition and Control section.

The same types of temperature sensors were installed on the respective reference modules in order to have the best correlation between the array and reference module temperature measurements. This choice was also made to allow evaluation of the sensors themselves via in-situ measurement of the reference module temperatures by alternate means. An extra type $\mathrm{T}$ thermocouple of the same model was also installed in the center of every reference module 
to connect to the built-in thermocouple temperature channels on the I-V tracer with maximum power tracker and load and provide a temperature measurement more easily correlated with the module measurements.

The same model thermocouple is installed on the corresponding reference modules for the Roof Horizontal and NZERTF arrays, but different model RTDs are installed at the Canopy, Roof Tilted, and Ground Arrays. At those arrays, the Omega RTD-3-F3102-72-T was used, which is very similar to the model of RTD installed on the reference modules, but does not have an adhesive backing and has a smaller subsequent contact area of $3.7 \mathrm{~mm} \mathrm{x}$ $4.7 \mathrm{~mm}$ (0.147 in. $\mathrm{x} 0.185$ in.). This RTD, which was installed first, was found to be relatively delicate and rather difficult to install due to its size. A visual comparison of the three temperature sensors is shown in Figure 3-9.

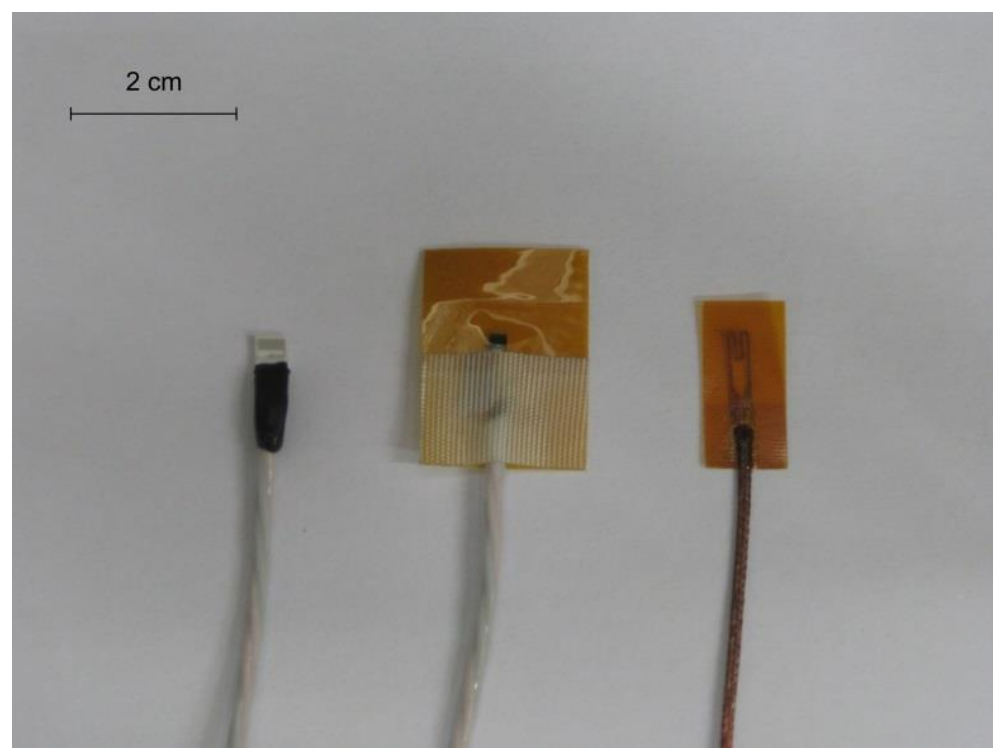

Figure 3-9 A visual comparison of the three types of module temperature sensors used for the reference modules and at the arrays: the RTD used at the Canopy, Roof Tilted, and Ground Arrays (left), the RTD used for the corresponding reference modules (center), and the thermocouple used at Roof Horizontal and NZERTF arrays and all of the reference modules (right).

\subsubsection{Calibrations}

All of the module temperature sensors were calibrated in the laboratory according to ASTM E220 [14]. According to the standard, dry calibrations were performed, with the test and reference temperature sensors packed in brass test tubes with thermally conductive aluminum oxide powder and immersed in a circulating temperature bath. All RTDs and thermocouples were within specifications, and the proportional and offset calibration coefficients and associated uncertainty were calculated for each sensor.

\subsubsection{Locations}

The sensors are mounted on the backsheets of the modules, with each sensor centered under a cell. Four sensors, either all RTDs or thermocouples, are installed on each module, positioned behind one center and three peripheral cells according to IEC 60891 [15]. The distribution of the sensors is intended to best capture temperature gradients in the module and for best calculating a single representative module temperature. An additional thermocouple of the same model used on other modules is also installed under a center cell. 


\subsubsection{Mounting and Alignment}

The temperature sensors are mounted to the module backsheet using Omegabond OB-101 thermally conductive epoxy and an Innotec 248DR, $57.2 \mathrm{~mm}$ ( $2.25 \mathrm{in}$.) diameter, $83 \mu \mathrm{m}$ ( $3.3 \mathrm{mil})$ thick round polyester adhesive film overlay, as shown in Figure 3-10. This method was derived as the combination of two of the best module back surface temperature measurement methods as determined by Smith, et al. [16], specifically the methods designated as positions $\mathrm{C}$ and $\mathrm{H}$. This combination allows accurate measurement of the surface temperature, minimally affects the surface temperature, results in a more precise bias from the true cell temperature, and provides reliably secure attachment to the surface. The best practices recommended by Smith, et al. were also followed when mounting the sensors, including minimizing the thickness of the epoxy under the sensor, minimizing the epoxy spread beyond the sides of the sensor, and using additional adhesive films and ties on the cable for strain relief to prevent the sensor from detaching. For the adhesive backed RTDs, the thermally conductive epoxy is applied to the adhesive surface, first removing the adhesive covers. The temperature sensors were aligned under the center of the respective cells by distance measurements and visual means.

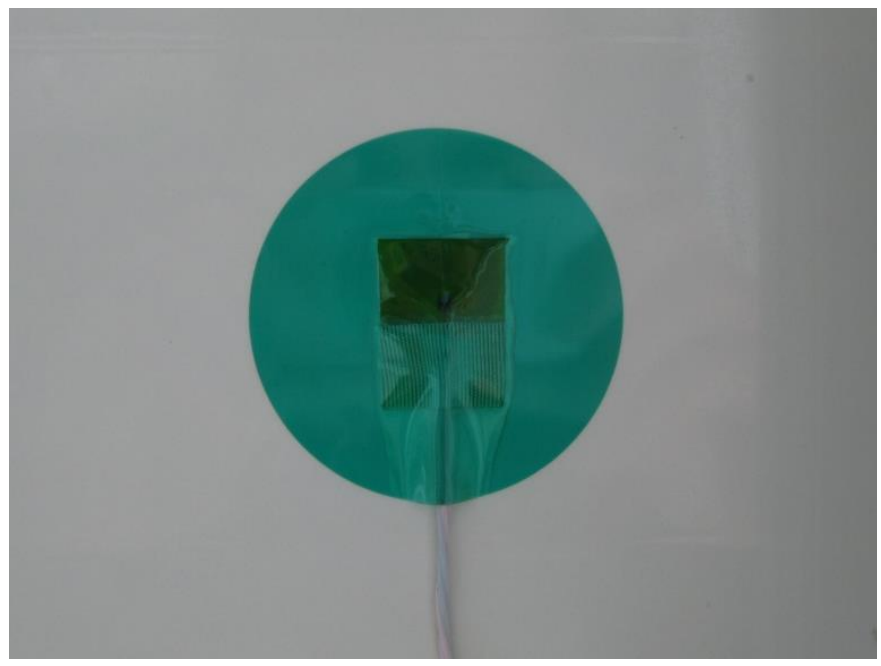

Figure 3-10 An RTD mounted on the back of a module using thermally conductive epoxy and an adhesive film overlay

\subsubsection{Wiring}

The module temperature sensors are wired directly to the data logger multiplexers. The RTD cable has four wires with the inner wire insulation (and outer jacket) made of PTFE (Teflon). PTFE has a much lower permittivity and subsequent capacitance than PVC and nearly all other wire insulation materials, resulting in faster settling times after excitation. The RTDs are connected to the extension cables using waterproof IP67 connectors. The TCs are connected to the extension cables using standard flat pin connectors housed in custom waterproof cable connector enclosures.

\section{Data Acquisition and Control}

\subsection{Data loggers}

\subsubsection{Components}

The weather station uses two Campbell Scientific CR1000-ST data loggers, as shown in Figure 4-1. 




Figure 4-1 The data acquisition enclosure at the weather station showing the data loggers, measurement and communication peripherals, battery backups, relays, and power converters and distribution blocks

This model data logger was chosen after considerations were made to the following:

- measurement accuracy

- processing power

- reliability over extended periods

- the ability to interface with a variety of peripherals

- form factor

- $\quad$ power draws and subsequently the needed size of the battery backup for extended power outages 
This data logger is also the same one chosen for the campus PV array DASs. The analog voltage, current, and thermocouple signals are multiplexed using Campbell Scientific AM25T solid-state multiplexers. The current carrying wires are first connected to Campbell Scientific CURS100 $100 \mathrm{ohm}$ current shunts to convert the current signals to voltage signals. The thermocouples are all connected to the same (lower) multiplexer and covered with the supplied insulated cover to reduce temperature gradients in the terminals and the resulting bias errors. These multiplexers are also uniform temperature references (UTR) which have an integrated RTD to measure the thermocouple reference temperature. The RTDs are multiplexed using one Campbell Scientific AM16/32B-ST relay multiplexer, located below the lower data logger in Figure 4-1. The serial devices are each connected to separate Campbell Scientific SDM-SIO1 serial communication modules. Redundant instruments and those measuring similar parameters are split between the two data loggers to maximize data availability in the event that one data logger stops operating.

Solid-state multiplexers are used because of their faster switching times and greater longevity than relay multiplexers, as measurements are needed on numerous channels at a one-second sample rate over an extended duration. A relay multiplexer is used for the RTD measurements instead of a solid-state multiplexer because the solid-state multiplexers cannot pass the currents needed to excite the RTDs. This restriction does limit the RTD sample period to greater than one-second, but this rate is acceptable because the module temperatures change at a slower rate than the irradiance. The separate serial communication modules are used instead of the serial communication channels on the data logger because there were not enough available channels.

The relay multiplexer is connected to the lower data logger through a Campbell Scientific 4WPB100 $100 \Omega$ fourwire half-bridge terminal input module. The bridge employs a high-accuracy $( \pm 0.01 \%)$, low temperature dependence $\left(<8 \times 10^{-6} /{ }^{\circ} \mathrm{C}\right)$ shunt to measure the current through the RTD, generated by the excitation voltage supplied by the data logger. A current limiting resistor is used in series with the shunt to allow for higher excitation voltages at the data logger, minimizing the relative noise in the excitation, while limiting the current and subsequent self-heating in the sensing resistor (RTD). Self-heating, which results in a measurement bias error, is caused by the excitation current passing through the sensor resistor.

A Campbell Scientific LR4 latching relay module is connected to each of the data loggers, via an SDI-12 bus connection. The ventilator fans and heaters are connected to the relays' terminals and power to them is controlled via their respective data logger.

A Campbell Scientific NL115 is connected to each of the data loggers' peripheral port and provides 10BASE-T Ethernet communications and a CompactFlash card slot interface for storing measurement data. An industrial quality 2 GB Synchrotech CFV-2GB-TSI-3524 card is used, which, like the data logger, can operate with high reliability for extended periods in outdoor conditions.

\subsubsection{Locations and Housing}

The data acquisition enclosure is located in an unconditioned room below the weather station, as shown in Figure 4-2. The enclosure is NEMA 4 rated and locked to control access, with an additional sensor installed to monitor when the door is open (at which time the data logger sends out an email alert). The humidity in the enclosure is regulated by sealing the conduit openings with duct seal compound and replacing desiccant packets on an as needed basis, with the humidity level monitored using a humidity indicator card. 


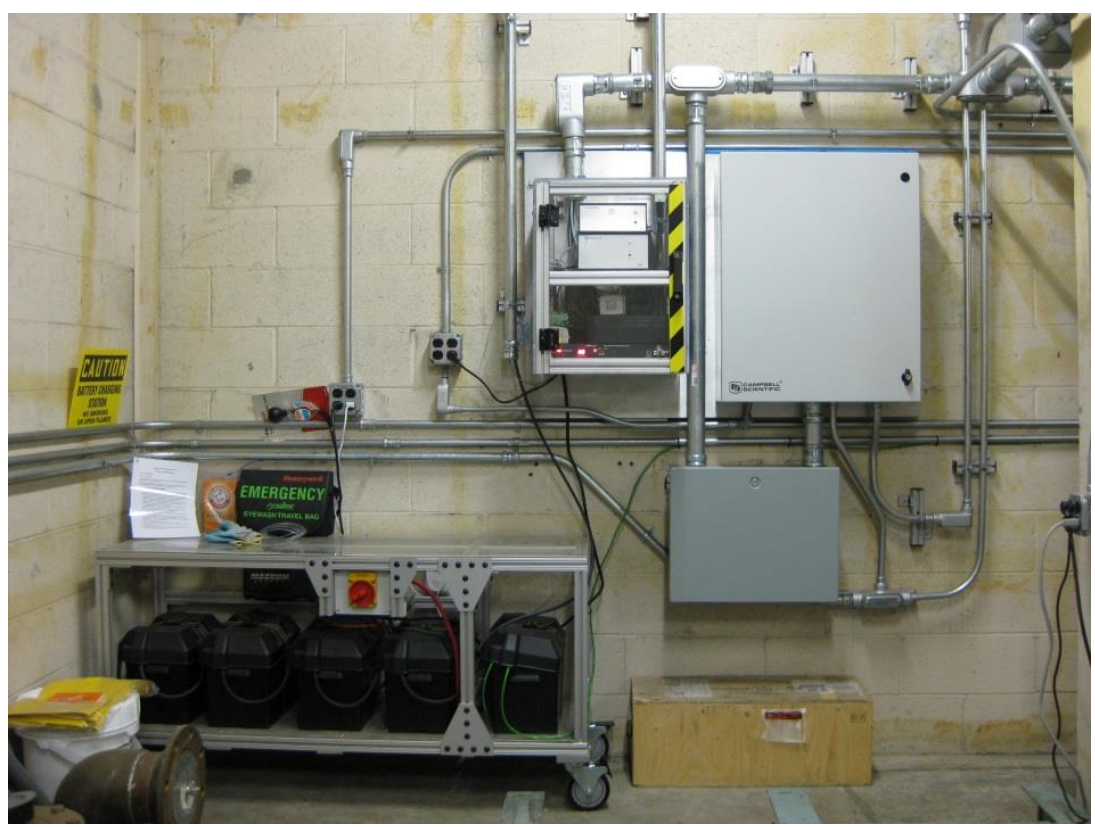

Figure 4-2 Location of the data acquisition enclosures and central UPS

Left of the main data acquisition enclosure is a smaller enclosure with clear acrylic sides that houses the EKO UV-A and UV-B converter boxes and the power supply for the rain gauge heater. Also in the enclosure are communications and power equipment for cameras on the roof, a network switch, and a remote power strip for controlling the power to select components.

\subsubsection{Wiring}

All wiring inside of the enclosures is low capacitance, high temperature PTFE insulated stranded wires with insulated ferrules crimped on their ends. Ferrule-terminated wires make troubleshooting and reworking easier and provide a more secure, lower contact resistance connection to the terminals. Jumper wires are connected between the low sides of the differential inputs and the respective ground terminals for the thermopile pyranometers, pyrheliometers, and the UV total radiometer to keep these electrically floating sensors from floating above the ground potential and out of the data logger's common mode range, which would decrease the accuracy of the measurements. The jumpers also keep these radiometers from potentially floating out of the measurable range entirely.

The Ethernet communication module on the data loggers connect via Cat6 Ethernet patch cables directly to the NIST network.

The data acquisition enclosure components are grounded to a central point on the enclosure. Grounding in a "starpoint" configuration minimizes the potential differences between the devices and therefore reduces any currents through the devices during a power surge event. The central point of the "star" is connected via the enclosure to the conduit which is locally grounded. The conduit was chosen instead of the ground wire fed from the nearby power distribution board because it provides a lower resistance path to ground and will not have an electrical choke effect when there is a sudden, high current surge from a nearby lightning strike, which occurs for a surge carrying wire inside of a ferrous conduit. The importance of proper grounding in the interest of equipment longevity cannot be overemphasized.

Four conduits connect to the data acquisition enclosure, separately carrying the AC power wires, the Ethernet communication patch cables, the sensor data cables, and the DC power cables for the ventilators. Excess lengths of 


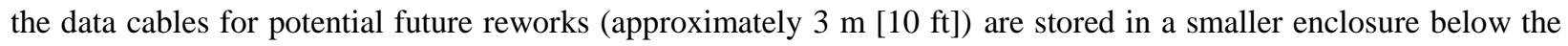
DAS enclosure in-line with the data conduit.

\subsubsection{Configuration}

\subsubsection{Sampling Rates and Parallel Processing}

The data loggers are programmed using the Campbell Scientific language CRBASIC. The programs measure all of the sensors every $1 \mathrm{~s}$, except for the RTDs and thermocouples measuring the reference modules' temperatures, which are measured every $10 \mathrm{~s}$. The slower RTD sampling rate is due to the slower relay multiplexers to which the RTDs are connected, but is not a restriction nonetheless because the module temperatures are not changing appreciably faster than every $10 \mathrm{~s}$. The UTR thermocouple reference temperature is measured before each set of thermocouple measurements. It takes longer than $1 \mathrm{~s}$ to measure, and poll and receive data from the sensors and instruments if done sequentially, so the program is run in "pipeline" mode which effectively executes some of the measurement steps in parallel.

\subsubsection{Time Synchronization}

In order to maintain time synchronization within $1 \mathrm{~s}$ between data loggers, the data loggers are instructed every morning just after midnight to synchronize with a local internet time server. This synchronization keeps the data loggers within $0.5 \mathrm{~s}$ of each other at all times. The data loggers are configured to always use local standard time (LST) to eliminate issues arising from the switch to and from daylight saving time (DST) and to allow easier comparisons and calculations.

\subsubsection{Channel Ranges}

The input voltage ranges for each measurement channel are explicitly chosen and fixed; auto-range is not used to eliminate the initial measurement needed to set the range, resulting in a shorter sampling time. The range determined by auto-range may also not be accurate for the irradiance and electrical measurements as they can fluctuate rapidly.

\subsubsection{Self-Calibration}

The data loggers are instructed to periodically self-calibrate to compensate for aging-induced and operating temperature-induced (Seebeck effect) drift. Voltage offsets are measured on each channel when the signal source is internally disconnected, using an internal voltage standard as a reference for all channels.

\subsubsection{Measurement Techniques}

Various techniques are employed for every measurement to more accurately measure the sensed value. The voltage signals, both direct from the sensor and those from a shunt when measuring current signals, are measured differentially instead of single-ended with respect to the data logger ground. This approach eliminates any voltage reference offsets and rejects capacitively coupled common-mode noise. The only exception to this approach is for the signals from the lower ultrasonic wind sensor, which are inherently single-ended. Before each of these measurements, the ground offset is measured and subtracted from the instrument signals to negate any bias.

Although considered, the electrically floating sensors are not pulled to ground before each measurement to null any common-mode voltage. Rather, jumper wires are connected between the low sides of the differential inputs of the radiometers and the respective ground terminals to keep them grounded. These data loggers combine nulling the common-mode voltage with open input detection, commonly used for thermocouples, into one function and neither can be individually implemented. The open input detection, which biases the high side of the differential input above the channel measurement range while grounding the low side, would not allow the thermopile-based radiometers' outputs enough time to stabilize before the measurements. No measurement channels in this DAS employ the common-mode nulling and open input detection function, including for the thermocouples measuring the temperature of two of the reference modules, in order to save measurement time. 
The settling times, the delay after the channel terminals are internally connected to the input amplifier and before the measurement is started, were chosen to be $10 \mathrm{~ms}$ for the thermopile-based radiometers and $3 \mathrm{~ms}$ for other analog signals. The longer settling time for the thermopile-based radiometers allows further reduction of voltage transients caused by channel switching, as they would have a larger relative magnitude since their voltage signals are much smaller.

The voltage signals are integrated for exactly $16.67 \mathrm{~ms}$. This integration time, the period of a $60 \mathrm{~Hz}$ waveform, rejects $60 \mathrm{~Hz}$ frequency components in the signal by cancelling them out. This noise is induced from nearby AC power sources, which operate at $60 \mathrm{~Hz}$ in the USA.

Each differential voltage measurement is performed twice, with the second time after the channel terminals are internally reverse-connected to the input amplifier. The two measurements are subtracted and divided by two to cancel any voltage offsets in the measurement circuitry, as well as any common-mode gain errors. Note that before each measurement the signal is allowed time to settle, which doubles the total settling time per measurement.

There is not enough available time in the $1 \mathrm{~s}$ scan period to employ all of the aforementioned techniques when measuring the four-wire RTDs, so tests were performed to identify those most beneficial in this application. The tests determined that a settling time of $3 \mathrm{~ms}$ was adequate and revealed that $60 \mathrm{~Hz}$ integration reduces significantly more noise than reversing the inputs and reversing the excitation, combined. Reversing the excitation is similar to reversing the inputs, but does so for the excitation and works to cancel any voltage offsets before and in the measurement circuitry (reversing the input cancels the offset in the measurement circuitry as well as the commonmode gain errors). Note that these two techniques each double the total settling time and combining both quadruples it. If there were a longer sampling period, then all three techniques would have been employed, even though the benefits of the two reversals are relatively small in this application.

The excitation for the RTDs is optimized by maximizing the measurement resolution of the voltage across the sensing resistor (RTD) while keeping the self-heating error, caused by the excitation current passing through the sensing resistor, below an acceptable level. Self-heating errors for $100 \Omega$ RTDs like the ones in this DAS are less than $0.001{ }^{\circ} \mathrm{C}\left(0.0018{ }^{\circ} \mathrm{F}\right)$ in still air when the voltage drop across the sensing resistor is less than approximately $25 \mathrm{mV}(6 \mu \mathrm{W})$ [17]. The optimal excitation voltage is therefore what results in a maximum sensor voltage of $25 \mathrm{mV}$, which occurs at the highest expected temperature, chosen conservatively to be $90{ }^{\circ} \mathrm{C}\left(194{ }^{\circ} \mathrm{F}\right)$. This temperature corresponds to a maximum resistance of $135 \Omega$. The optimal excitation voltage is calculated for the half-bridge and current-limiting resistor in Figure 4-3 using Equation (1), neglecting the wire resistances. The equation is calculated using values of the measurement bridge resistors at the low end of their respective tolerance ranges, resulting in a higher current and subsequently higher RTD voltage. If the tolerances are not accounted for, this potentially higher RTD voltage could be greater than the selected measurement range. 


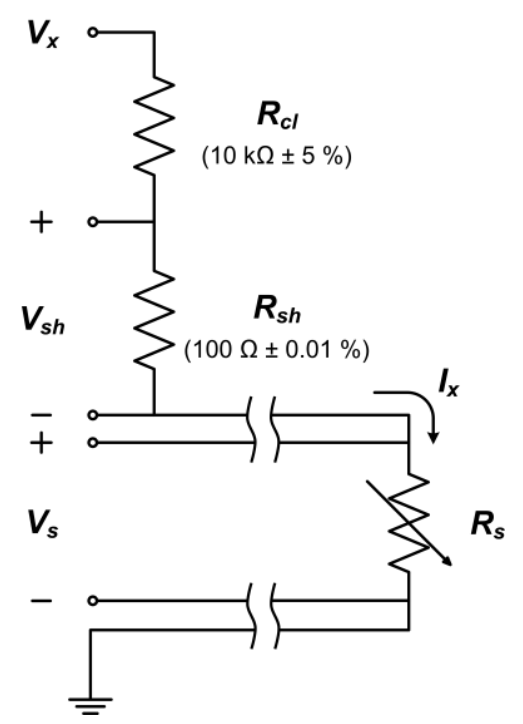

Figure 4-3 Half-bridge for measuring distant RTDs to nullify effect of wire resistances

$$
V_{x}=\frac{V_{s, \text { max }}}{R_{s, \text { max }}}\left(R_{c l, \text { min }}+R_{s h, \text { min }}+R_{s, \text { max }}\right)
$$

where:

$V_{x}=$ excitation voltage

$V_{s}=$ sensing voltage

$R_{s}=$ sensing resistor $(\mathrm{RTD})$

$R_{c l}=$ current limiting resistor

$R_{s h}=$ completion (shunt) resistor

$V_{s h}=$ shunt voltage

$I_{x}=$ excitation current

The optimal excitation, calculated to be $1.8 \mathrm{~V}$, is kept on only during the measurement to further reduce the selfheating errors. The measurement equation for the half-bridge, when reduced, becomes the ratiometric relation $R_{s}=R_{s h} \cdot\left(V_{s} / V_{s h}\right)$. The temperature of the RTD is then determined from the resistance using the inverse of the Callendar-Van Dusen equation according to the ASTM E1137-04 [18] standard.

Timeouts for the serial communicating instruments, the time after polling the instrument waiting for a reply, were carefully chosen to be the maximum time the instrument normally takes to respond to a request. A flag in the data logger programs can be manually set while the program is running to stop polling individual instruments in the case where they are temporarily unresponsive. Setting this flag can speed up the program and avoid missed measurements while the data logger would normally be waiting the full timeout period for a response.

\subsubsection{Control}

The data loggers regulate the power to the UV-A and UV-B radiometers, the rain gauge heater, the POA flat-plate silicon irradiance sensors, the weather transmitter heater, and the fans and heaters in the ventilators when external power to the DAS is off and the data loggers, instruments, and other equipment are operating on battery power. 
These instruments, fans, and heaters consume the most power from the UPSs and are regulated to allow them to operate between approximately 2.6 days and 4.4 days on battery power.

Power to the UV-A and UV-B converter boxes is turned off at night between 20:30 and 04:00 LST using a Synaccess NP-0801DS remote power strip controlled by the lower data logger via a serial communication module. Power to the POA flat-plate silicon irradiance sensors is also turned off at night by the top data logger via its switched $12 \mathrm{~V}$ terminal. The rain gauge heater is controlled using the remote power strip, the weather transmitter heater is controlled via serial commands, and select ventilator fans and heaters are controlled using the latching power relays. Power to these latter devices are regulated to best minimize frost, snow, and ice accumulation.

When there is power to the data acquisition enclosures, and the ambient temperature drops below $2{ }^{\circ} \mathrm{C}$, the rain gauge heater is turned on and the ventilator heater power for the GHI measuring pyranometers is increased from its normal $50 \%$ level to $100 \%$.

The lower data logger also remotely toggles the power to the campus PV Roof Tilted array data logger via a power relay every other day at 01:00 LST or when the data logger is unresponsive. This data logger, due to its high utilization, drops its communications every few days and needs a power reset to restore it. The relay is controlled over the public NIST network.

\subsubsection{Data storage and processing}

Measurements are stored on the memory card as either 16-bit floating point, 16-bit unsigned, 32-bit floating point, or 32-bit signed integer data types according to the needed range and precision of the individual measurements. This selective allocation conserves storage space and increases processing speeds in the data logger and server. All measurements are saved every one-second, including the RTD and thermocouple measurements, resulting in nine duplicate RTD/thermocouple measurements saved every 10-second sample period. All measurements are also either averaged or the minimum, maximum, sum, median, or standard deviation calculated for each minute, whichever is more appropriate, and these values are saved. The one-minute values are calculated from the samples taken between $1 \mathrm{~s}$ and $60 \mathrm{~s}$, inclusive, preceding the recorded minute time. The wind measurements are processed according to EPA guidelines to produce the mean horizontal wind speed, the unit vector mean wind direction, and the standard deviation of wind direction calculated using the Yamartino algorithm [19].

The 2 GB of storage can store 212 days to 244 days of measurements from the lower and top data loggers, respectively, for times when the communications are down. The storage is configured as ring memory, where the oldest data is overwritten when the memory card is full.

\subsection{Spectroradiometers}

The two spectroradiometers, as described in section 3.6 are connected to separate converter boxes that power the spectroradiometers and relay the measurements using a serial communications connection. The two converter boxes are connected to a dedicated Windows 7 computer running a custom LabVIEW [20] program. This program, or virtual instrument (VI), samples and saves the spectrums every one minute. The program also combines the measurements from $335.6 \mathrm{~nm}$ to $925.5 \mathrm{~nm}$ and from $926.5 \mathrm{~nm}$ to $1712.6 \mathrm{~nm}$ from the two different instruments into one continuous spectrum. This spectrum is also saved every one minute.

\subsection{Reference Modules}

The modules and their respective centrally placed thermocouples are connected to a Daystar Multi-Tracer 5 (MT5) I-V curve tracer with maximum power tracker and load system, as shown in Figure 4-4. (The set of four temperature sensors on each module are connected to a data logger multiplexer.) The irradiance sensors are first connected to a data logger multiplexer via current shunts to convert the current signals to voltage signals, and these voltage signals are also wired over to auxiliary inputs on the maximum power tracker and load system to obtain a second set of measurements. 


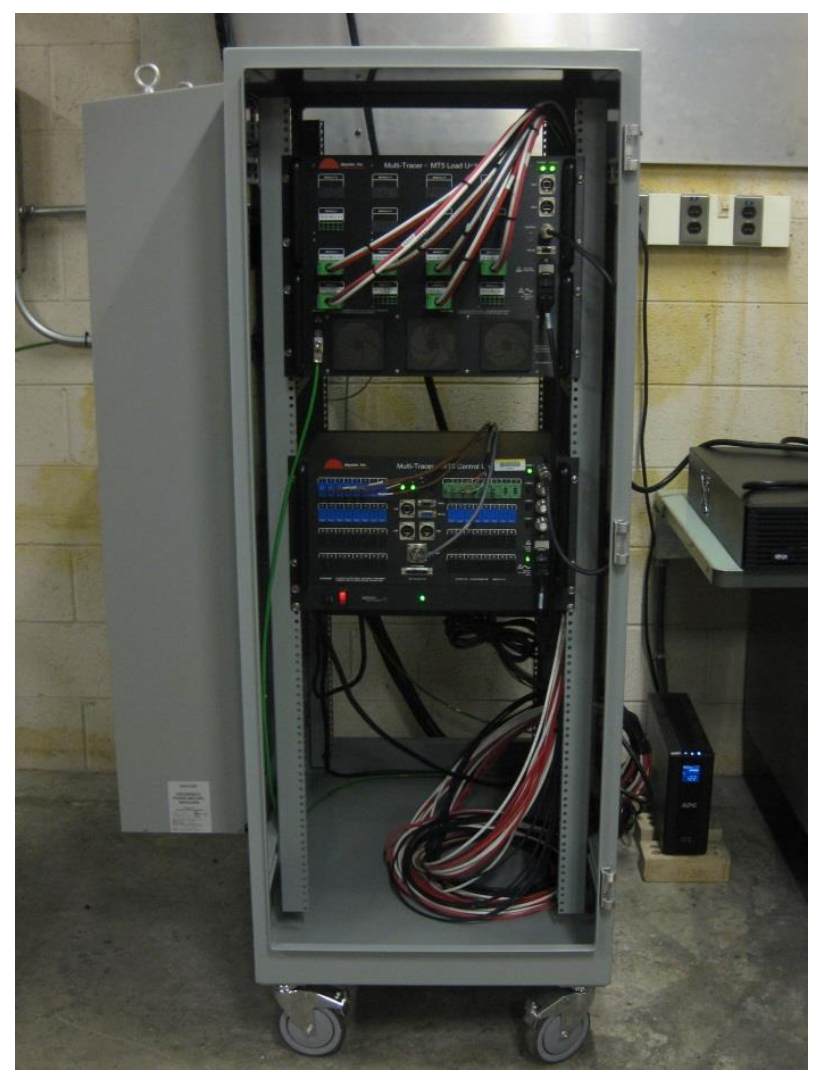

Figure 4-4 The I-V curve tracer with maximum power tracker and load

The I-V tracer and maximum power tracking system performs an I-V trace for each module every minute, integrating every current and voltage reading for $100 \mu \mathrm{s}$. The curves are saved along with measurements of the respective thermocouple and irradiance sensor before and after each trace. At all other times, the system maximum power tracks each module, measuring the maximum power voltage and current and the corresponding thermocouple and irradiance sensor, sampling every one second and averaging and saving every minute. All measurements are saved to internal memory. The MT5 system does not adjust its clock for DST, which allows for easier comparison with the measured data from the data loggers, which also do not adjust for DST. The system was calibrated by the manufacturer and verified to be within specifications.

\subsection{Cameras}

\subsubsection{Module and Instrument}

Images of the instruments, reference modules, and the PV array on the NZERTF are taken using cameras installed at the weather station. The images are used to capture the shading, snow, dew, and frost, and any other obstructions or damage to the instruments and modules. An Axis Q6032-E pan-tilt-zoom (PTZ) network camera is located at the north end of the reference module platform in the east-west center, as shown in Figure 4-5. This camera is programmed to take images of the entire south half of the weather station, close-up images of the instruments on the east table and solar tracker, images of the entire NZERTF, and a close-up image of the PV array on the NZERTF. 




Figure 4-5 The PTZ camera that records images of the instruments and NZERTF PV array

The camera is configured for constant white balance, auto exposure, and to use an IR cut filter during the day but not at night to increase sensitivity. The cameras, like the data loggers, are configured to not adjust their clocks for DST for easier comparison with the measured data. The cameras take $704 \times 480$ resolution images, which are saved as uncompressed JPEG images on an internal 32 GB SanDisk Extreme SD card. The cameras take images every five minutes during the day (04:00 to 20:00 LST) and every hour all day. The camera communicates over the NIST private network and is powered using Power over Ethernet (PoE). The midspan, for combining the power and Ethernet, and a network switch are housed in the enclosure next to the main data acquisition enclosure, as shown in Figure 4-2.

Two additional cameras, Campbell Scientific CC5MPXs, are located on the west table. These cameras take images of the reference modules and view the solar tracker. The cameras do not adjust for DST and take $2592 \times 1944$ resolution images saved as uncompressed JPEG images on an internal 32 GB SanDisk Extreme SD card. No other settings are configurable. The camera viewing the modules is programmed to take a fixed zoom image every five minutes during the day (04:00 to 20:00 LST) and every hour all day; the camera viewing the solar tracker does not currently record images. The cameras communicate over the NIST private network and are powered using separate cables.

\subsubsection{All Sky}

Images of the entire sky, horizon to horizon, are taken using an all sky camera. The camera is an Alcor System OMEA-2.0M-HCA equipped with a fisheye lens, an auto-iris, and an integrated heater. The camera CCD has an IR cut filter and records 24 bit ( 8 bit dynamic range) color $1600 \times 1200$ resolution ( 2 MP) images. Paired with a Fujinon FE185C046HA-1 fisheye lens having a $1.4 \mathrm{~mm}$ focal length and a $185^{\circ}$ x $185^{\circ}$ field of view, this camera produces full horizon to horizon color images. However, there are unexposed areas on the sides of the image, giving the images an effective resolution of about $1125 \times 1125$.

The camera has an auto-iris mechanism controlled by a photodiode that adjusts the lens aperture between F1.4 to F8 to allow nighttime, low-light, and clear sky exposures, with a typical daytime aperture setting of F5.6. An external ambient temperature and humidity sensor is used to control an integrated heater to keep the camera dome free of fog and frost. The camera is mounted to a custom mount that also holds the temperature and humidity sensor, as shown in Figure 4-6. 


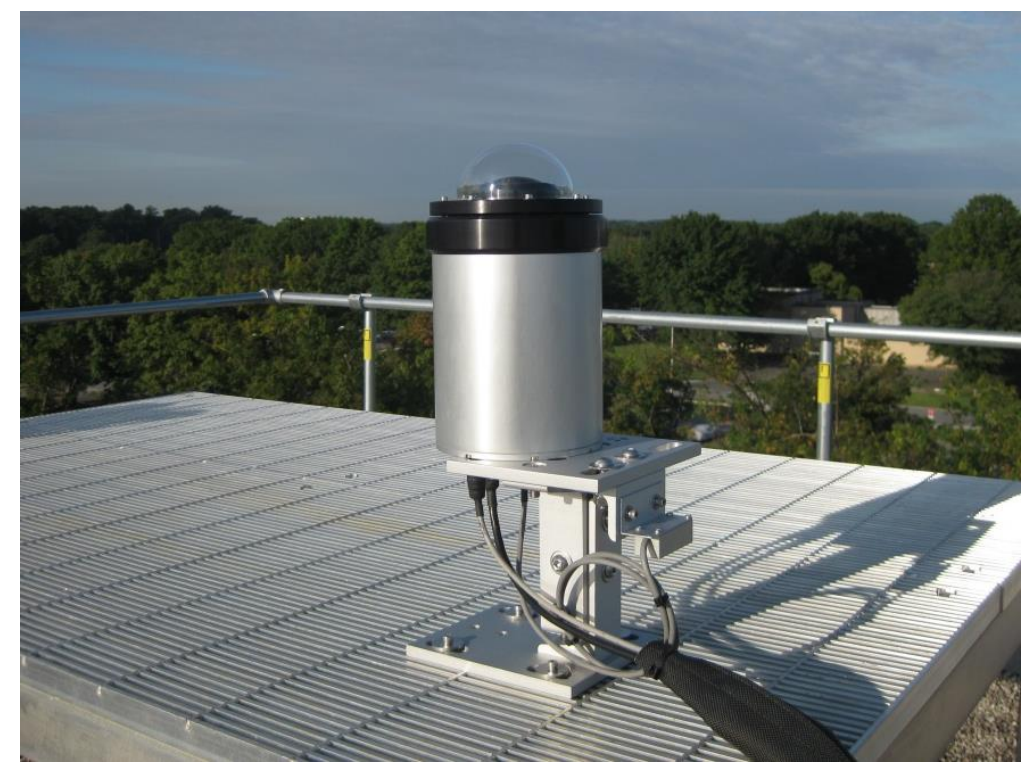

Figure 4-6 The all sky camera with the ambient temperature and humidity sensor installed on a custom mount on the west table

The camera communicates over USB and is wired to a dedicated Windows 7 computer and a power supply using separate cables. The computer runs software by the manufacturer that manages the camera operation and image acquisition. The software is configured for automatic white balance, gain, and exposure, with a typical exposure time of $1 \mathrm{~ms}$. Images are taken every eight seconds, although for the first few months of operation images were taken every one minute. Only hourly images are kept for those taken during nighttime periods in order to conserve storage. The images are timestamped with the local daylight time, and there is no option to disable DST. The images are saved as uncompressed JPEG files, with an example image shown in Figure 4-7.

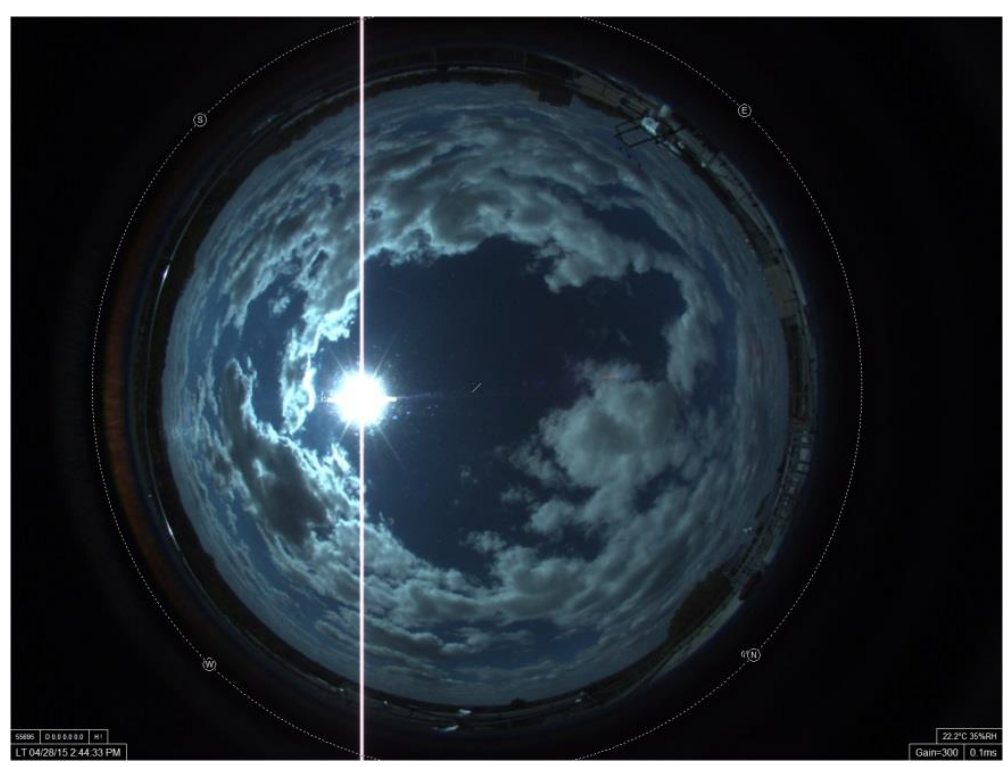

Figure 4-7 An image taken by the all sky camera 


\section{Backup Power}

\subsection{Data loggers}

The data loggers are each battery-backed using separate Genesis NP24-12 $12 \mathrm{~V}, 24 \mathrm{~A} \cdot \mathrm{h}(288 \mathrm{~W} \cdot \mathrm{h})$ sealed rechargeable lead acid batteries connected to Campbell Scientific $\mathrm{CH} 200$ charging regulators. This regulator charges the battery and switches between line and battery power, providing an uninterrupted power supply (UPS) to the data logger and all other peripherals in the enclosure. The data loggers communicate with the charging regulators to obtain electrical measurements via an SDI-12 bus connection, the same used by the latching relay modules. The UPSs will provide 4.4 days of power to the top data logger and connected peripherals and 2.6 days of power to the lower data logger and peripherals when there is no external power feeding the enclosure, even during high power draw conditions (e.g., while periodically heating the weather transmitter in winter and running the ventilators). A breakdown of the energy draws is shown in Figure 5-1.

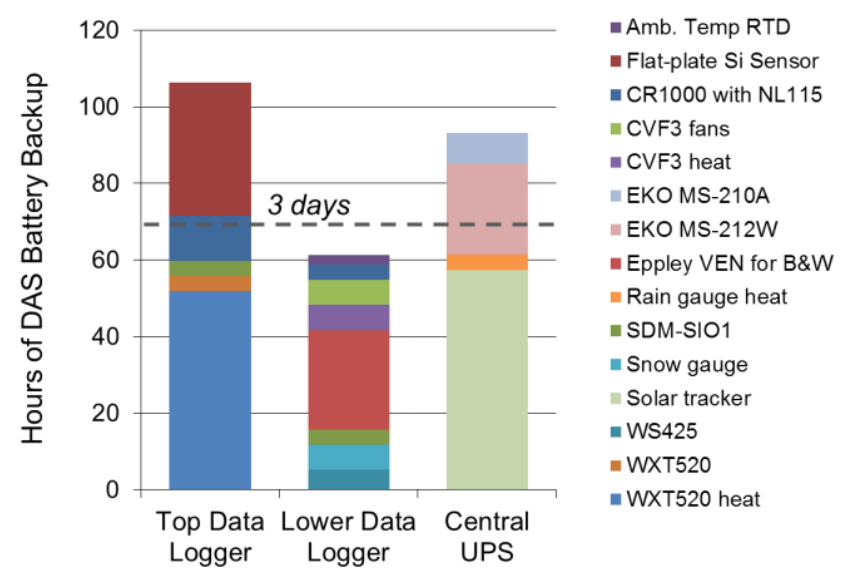

Figure 5-1 Breakdown of the DAS energy draws and UPS backups

Power from each data logger UPS is distributed to the respective data logger, peripherals, and an array of terminal blocks for the different sensors via a Campbell Scientific A105 terminal expansion adapter on the charging regulator. The line inputs of the charging regulators for the UPSs are each connected to 120 VAC to 24 VDC power converters. These two power converters are connected to $120 \mathrm{VAC}$ feeding the enclosure via terminal blocks and a single AC circuit breaker.

\subsection{Central UPS}

The solar tracker, UV-A and UV-B radiometer converter boxes, and the rain gauge heater are battery backed with a wet cell battery bank. The battery bank consists of five Crown 12CRP165 12V, $150 \mathrm{~A} \cdot \mathrm{h}$ (72 hour discharge rate) batteries connected in parallel with a Magnum Energy MMS1012-G pure sine wave inverter/battery charger/automatic transfer switch, as shown in Figure 4-2. The battery bank has a $7.6 \mathrm{~kW} \cdot \mathrm{h}$ capacity at a 72 hour (3 day) discharge rate, factoring in the inverter's $84 \%$ efficiency. This supplies over three and a half days of continuous backup power when the UV-A and UV-B radiometers are turned off at night and the tipping bucket rain gauge heater is limited to five hours of heating per day. An inline fuse, DC disconnect switch, battery temperature sensor, and hydrogen sensor are installed for safety.

\subsection{Distributed UPSs}

The three cameras, the two spectroradiometers, the sky camera, and each of the two computers acquiring data and images from the spectroradiometers and sky camera are battery-backed with individual UPSs with approximately 18 Wh capacities. 


\section{Data Archiving and Monitoring}

Campbell Scientific LoggerNet Admin is used to manage the weather station data loggers in addition to the data loggers in the campus PV DASs. It is installed on a network server running Windows Server 2008 R2. LoggerNet Admin runs as a service, running whether or not a user is logged in and starts immediately after the server restarts. LoggerNet is configured to import data from the data loggers every minute, leaving a copy on the data loggers as a backup to be overwritten later. The data are saved on the server as Campbell Scientific TOA5 formatted plain text files, one for each of the seven defined data logger tables on the two data loggers, including the one-minute aggregate tables.

The data files are imported to a MySQL database every minute by Vista Data Vision (VDV) Enterprise by Vista Engineering, also installed on the server. VDV is configured to send email alerts when data values are outside of defined ranges and when the data files are not being updated. Custom dashboards with plots of select measurements are updated by VDV every minute and provide an overview of the system health. These dashboards are displayed in a web interface hosted by the server, with the main data dashboard shown in Figure 6-1. In addition to the dashboards, custom plots of various types, tables, logs of alarms, completeness of the database, and a viewer for the hourly camera images are also provided in the web interface. This web interface is currently only available inside the NIST firewall, but a public data portal with the ability to download data will be made available. In the meantime, interested modelers and analysts who would like to use these data in collaboration on new research can contact the author.

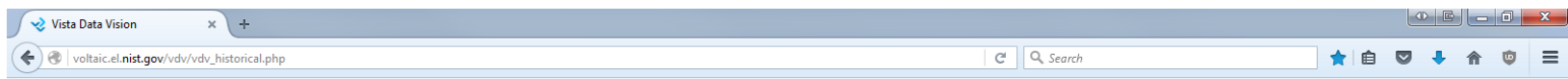

\section{NLT}

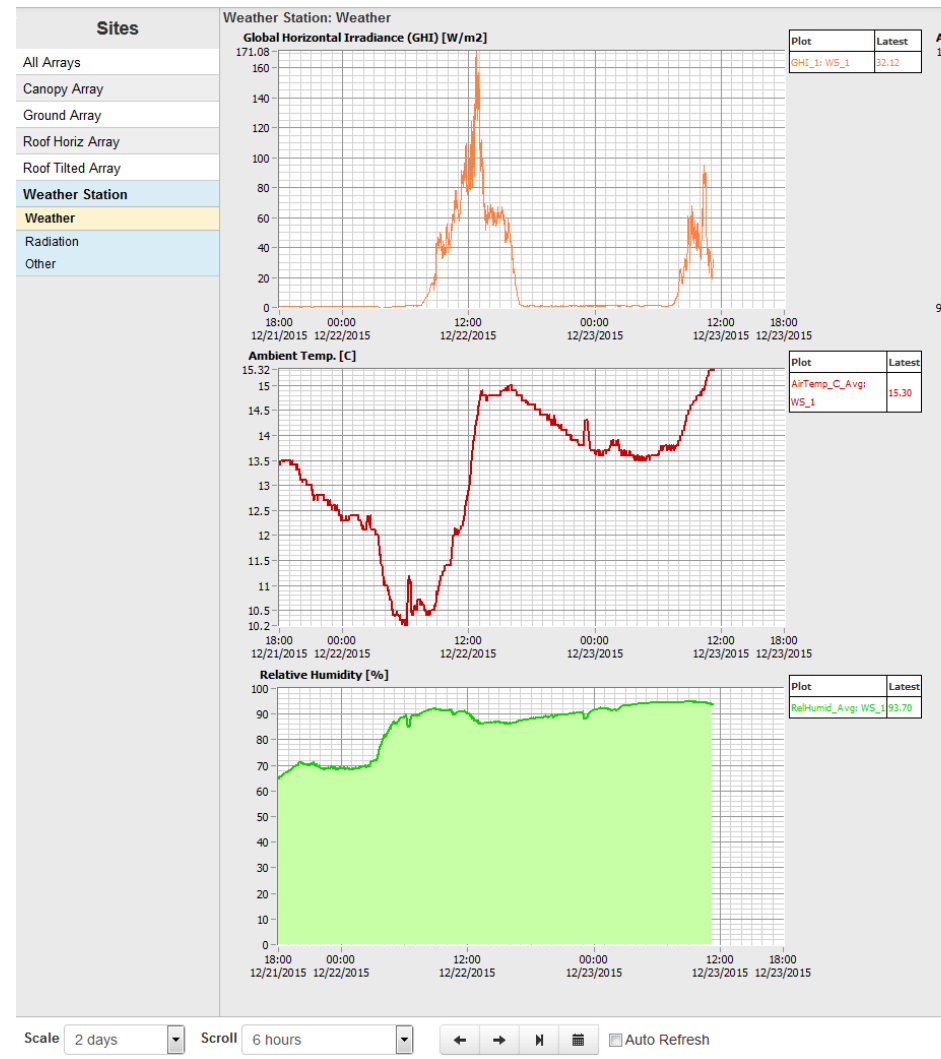

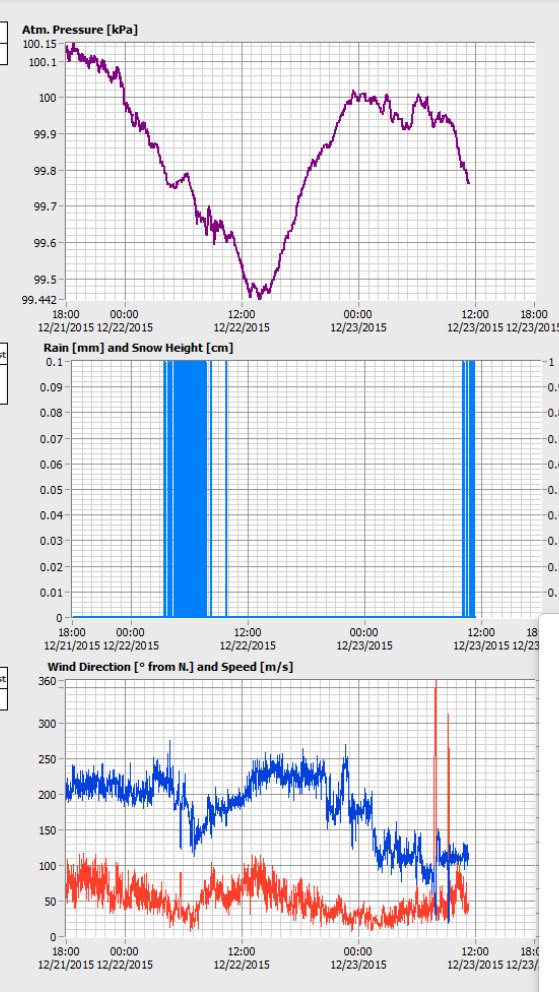
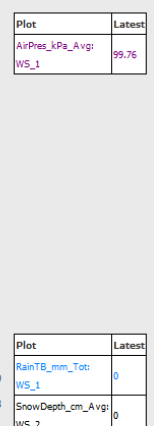$$
0.4
$$$$
0.2
$$$$
\text { 弫 Histogram }
$$$$
\text { E Sort by Size }
$$$$
E_{x} \text { XY Graph }
$$$$
\text { (2) Wind Rose }
$$$$
\text { Distribution Wind Rose }
$$$$
\text { Filter Wind Rose }
$$$$
\text { 公 Diurnal }
$$$$
\text { Relative Plot }
$$$$
\text { Everlay Graph }
$$$$
\text { [1- Intensity Plot }
$$$$
\text { i Page Information }
$$$$
\text { P Print }
$$$$
\text { 年 }
$$$$
\text { 回 Save D }
$$$$
\text { 西 Table }
$$$$
\begin{array}{ll|l}
\Delta 0 & = & +
\end{array}
$$

Figure 6-1 The main data dashboard for the weather station 
Data from the spectroradiometers, I-V curve tracer and maximum power tracking system, and images from the cameras are copied to network attached storage every 30 minutes by an FTP client on the server run as a scheduled task. A custom script, also run as a scheduled task, monitors and sends alerts when these data files are not being transferred. VDV monitors and sends alerts when new images from each camera are not being transferred. All data and images on the server, including data from the data loggers, are continually backed up to offsite cloud storage.

\section{Uncertainty}

Uncertainties for the collected data are not listed because a complete uncertainty analysis is outside the scope of this report, but one will be presented for each measurement in a forthcoming paper. Sensor and instrument-level uncertainties are not given as they are only part of the system-level values, and therefore can be misleading. Furthermore, they do not account for the error between the measurand, the quantity of interest, and the realized quantity, the quantity measurable by the sensor.

\section{Maintenance}

The data dashboards are checked every weekday for any apparent problems in the DAS. The irradiance sensors are cleaned every other day, minus weekends, using cleanroom wipes moistened with a $6 \%$ isopropyl/94 \% deionized water mixture, dried with optical tissue, and blown-off with compressed air. Any ice buildup is first melted using an ethanol solution of the same concentration. The reference modules are cleaned on an as-needed basis. A log is kept of the dates and times when the sensors at the different arrays are cleaned. Instrument and solar tracker level are continually checked, as is their desiccant, and the tracker pointing accuracy is verified using the diopters on the pyrheliometers. The rain gauge orifice is cleaned every couple weeks.

The data files on the server grow indefinitely, so once a week a custom script is run that pauses the data importation from the data loggers and runs the Campbell Scientific program File Format Convert that splits the files into separate daily files for easier archiving and use.

The desiccant in the data logger enclosures is checked every couple months and replaced according to the humidity indicator in the enclosure. The solar tracker gears are greased yearly and a cold weather cover is installed over it in the late fall and removed in the early spring. Ventilator and multi-tracer filters are replaced on a yearly basis or as needed. Thermopile pyranometers, pyrheliometers, and the pyrgeometer are replaced every 12 to 18 months with newly calibrated pyranometers from NREL; the UV radiometers and spectroradiometers are calibrated every 18 months. A log is kept of these instrument replacements and calibrations, which also contains all other maintenance including when sensors, instruments, and devices fail and are replaced.

\section{Acknowledgements}

The author wishes to thank all those who contributed time and effort planning, constructing, and implementing the infrastructure needed for the data acquisition system described in this report. Special thanks to Brian Dougherty of NIST's Engineering Laboratory's (EL's) Energy and Environment Division for logistical, construction, and maintenance support. Thanks to Luis Luyo, also of EL's Energy and Environment Division, for constructing the infrastructure for the reference modules, and to Jeffrey Sze for early testing of the systems.

\section{References}

[1] Matthew Boyd, High-speed monitoring of multiple grid-connected photovoltaic array configurations, National Institute of Standards and Technology. NIST Technical Note 1896 (2015). http://dx.doi.org/10.6028/NIST.TN.1896

[2] A.H. Fanney, V. Payne, T. Ullah, L. Ng, M. Boyd, F. Omar, M. Davis, H. Skye, B. Dougherty, B. Polidoro, W. Healy, J. Kneifel, and B. Pettit, Net-zero and beyond! Design and performance of NIST's net-zero energy residential test facility, Energy Build. 101 95-109 (2015). 
[3] K. Lynn, SunShot, (2011). http://www.solar.energy.gov/pdfs/doe_lynn_pv_validation_2011_aug.pdf (Accessed on Sept. 11, 2015)

[4] J. Granata, PV performance and reliability validation capabilities at Sandia National Laboratories and the National Renewable Energy Laboratory, (2011). http://energy.gov/sites/prod/files/2014/01/f7/pv_manufacturing_workshop_2011_march_granata.pdf (Accessed_on Sep. 11, 2015)

[5] J. Newmiller, Validation information for PV power system project review, (2011). http://www.solar.energy.gov/pdfs/dnv_newmiller_pv_validation_2011_aug.pdf (Accessed on Sep. 11, 2015)

[6] Sandia National Laboratories, PV validation and bankability workshop - August 31, 2011 - Survey Results, (2011). http://energy.gov/sites/prod/files/2014/01/f7/pv_vb_surveyresults.pdf (Accessed Sep. 23, 2015)

[7] Stephen Wilcox, National solar radiation database 1991-2010 update: user's manual, National Renewable Energy Laboratory, (2012).

[8] NOAA, DoD, FAA, and United States Navy, Automated Surface Observing System (ASOS) User's guide, (1998). http://www.nws.noaa.gov/asos/pdfs/aum-toc.pdf

[9] SketchUp Pro, Trimble Navigation Limited, Sunnyvale, California USA (2012).

[10] I. Reda, D. Myers, and T. Stoffel, Uncertainty estimate for the outdoor calibration of solar pyranometers: a metrologist perspective, NCSLI Meas. 3 (4), 58-66 (2008).

[11] Kipp and Zonen, CHP 1 Pyrheliometer Instruction Manual, (2008).

[12] Howard W. Yoon and Charles E. Gibson, NIST measurement services: spectral irradiance calibrations, National Institute of Standards and Technology. NIST Special Publication 250-89 (2011). http://www.nist.gov/calibrations/upload/sp250-89.pdf

[13] Omega Engineering, Temperature handbook and encyclopedia, (2010).

[14] ASTM, Standard Test Method for Calibration of Thermocouples By Comparison Techniques, ASTM International, (2007).

[15] IEC, Photovoltaic devices - Procedures for temperature and irradiance corrections to measured I-V characteristics, International Electrotechnical Commission (IEC), Geneva, Switzerland (2009).

[16] R.M. Smith, S. Kurtz, and B. Sekulic, Back-of-module temperature measurement methods, SolarPro 90-104 (2011).

[17] Campbell Scientific, CR1000 Measurement and Control System, (2013). https://s.campbellsci.com/documents/us/manuals/cr1000.pdf (Accessed Sep. 23, 2015)

[18] ASTM, Standard Specification for Industrial Platinum Resistance Thermometers, ASTM International, (2008).

[19] EPA, Meteorological Measurements, Quality Assurance Handbook for Air Pollution Measurement Systems, (2008).

[20] LabVIEW, National Instruments, (2014). 


\section{Appendix A. The Saved Data Values From Each Data Logger}

Table A-1 The Saved Data Values From Each Data Logger

\begin{tabular}{|c|c|c|c|c|}
\hline Variable Name & Units & Description & $\begin{array}{l}\text { One-Minute } \\
\text { Aggregation }\end{array}$ & $\begin{array}{l}\text { Top }(T) / \\
\text { Lower }(\mathrm{L}) \\
\text { Data Logger }\end{array}$ \\
\hline AirMass & - & Absolute air mass & Average & $\mathrm{T} / \mathrm{L}$ \\
\hline AirPres_kPa & $\mathrm{kPa}$ & Atmospheric pressure & Average & $\mathrm{T}$ \\
\hline AirTemp_C & $\mathrm{C}$ & $\begin{array}{l}\text { Outdoor ambient temperature } 5.59 \mathrm{~m} \text { above } \\
\text { roof }\end{array}$ & Average & $\mathrm{T}$ \\
\hline AM25TRefTemp_C & $\mathrm{C}$ & Thermocouple UTR reference temperature & Average & $\mathrm{L}$ \\
\hline AmbTemp_C & $\mathrm{C}$ & $\begin{array}{l}\text { Outdoor ambient temperature } 1.07 \mathrm{~m} \text { above } \\
\text { roof }\end{array}$ & Average & $\mathrm{L}$ \\
\hline AmbVent_rpm & $\mathrm{rev} / \mathrm{min}$ & $\begin{array}{l}\text { Mean ambient temperature ventilator fan } \\
\text { speed }\end{array}$ & Average* & $\mathrm{L}$ \\
\hline Battery_A & A & Current to UPS battery, neg. = discharging & Average & $\mathrm{T} / \mathrm{L}$ \\
\hline Battery_V & $\mathrm{V}$ & Charge voltage of UPS battery & Min & $\mathrm{T} / \mathrm{L}$ \\
\hline ChgSource & - & $\begin{array}{l}\text { Charging regulator power source } \\
0=\text { none } \\
1=\text { solar terminals } \\
2=\text { continuous terminals }\end{array}$ & Min & $\mathrm{T} / \mathrm{L}$ \\
\hline ChgState & - & $\begin{array}{l}\text { State of charging regulator; } \\
-1=\text { regulator fault } \\
0=\text { no charge } \\
1=\text { current limited charging } \\
2=\text { cycle charging } \\
3=\text { float charging } \\
4=\text { battery test }\end{array}$ & Min & $\mathrm{T} / \mathrm{L}$ \\
\hline CkBatt & - & $\begin{array}{l}\text { Status of UPS battery; } \\
0=\text { normal } \\
1=\text { check battery }\end{array}$ & Max & $\mathrm{T} / \mathrm{L}$ \\
\hline CR1000Temp_C & $\mathrm{C}$ & $\begin{array}{l}\text { Temperature of the data logger front } \\
\text { terminal panel }\end{array}$ & Average & $\mathrm{T} / \mathrm{L}$ \\
\hline Declination_deg & $\circ$ & Earth's declination angle & Average & $\mathrm{T} / \mathrm{L}$ \\
\hline DoorOpen & - & $\begin{array}{l}\text { Door sensor for DAS enclosure; } \\
-1=\text { open, } 0=\text { closed }\end{array}$ & Min & $\mathrm{T}$ \\
\hline Hail_hitssqrem & hits $/ \mathrm{cm}^{2}$ & Hail count & Sum & $\mathrm{T}$ \\
\hline Load_A & A & $\begin{array}{l}\text { Current supplied to load (UPS) from } \\
\text { charging regulator }\end{array}$ & Average & $\mathrm{T} / \mathrm{L}$ \\
\hline PwrStripState & - & State of remote power strip, bit field & Min & $\mathrm{L}$ \\
\hline Pyra1_mV & $\mathrm{mV}$ & $\begin{array}{l}\text { Millivolt output from thermopile } \\
\text { pyranometer, south table position }\end{array}$ & Average & $\mathrm{T}$ \\
\hline Pyra1temp_C & $\mathrm{C}$ & $\begin{array}{l}\text { Thermopile pyranometer case temperature, } \\
\text { south table position }\end{array}$ & Average & $\mathrm{T}$ \\
\hline
\end{tabular}




\begin{tabular}{|c|c|c|c|c|}
\hline Pyra2_mV & $\mathrm{mV}$ & $\begin{array}{l}\text { Millivolt output from thermopile } \\
\text { pyranometer, north table position }\end{array}$ & Average & $\mathrm{L}$ \\
\hline Pyra2temp_C & $\mathrm{C}$ & $\begin{array}{l}\text { Thermopile pyranometer case temperature, } \\
\text { north table position }\end{array}$ & Average & $\mathrm{L}$ \\
\hline Pyrad1_mV & $\mathrm{mV}$ & $\begin{array}{l}\text { Millivolt output from diffuse-measuring } \\
\text { pyranometer, east tracker position (when } \\
\text { pointing south) }\end{array}$ & Average & $\mathrm{T}$ \\
\hline Pyrad2_mV & $\mathrm{mV}$ & $\begin{array}{l}\text { Millivolt output from diffuse-measuring } \\
\text { pyranometer, west tracker position (when } \\
\text { pointing south) }\end{array}$ & Average & $\mathrm{L}$ \\
\hline PyraS1_Wm2 & $\mathrm{W} / \mathrm{m}^{2}$ & $\begin{array}{l}\text { Millivolt output from domed-diffused } \\
\text { silicon-cell pyranometer }\end{array}$ & Average & $\mathrm{L}$ \\
\hline Pyrg1_mV & $\mathrm{mV}$ & Millivolt output from pyrgeometer & Average & $\mathrm{T}$ \\
\hline Pyrg1temp_C & $\mathrm{C}$ & Pyrgeometer case temperature & Average & $\mathrm{T}$ \\
\hline Pyrh1_mV & $\mathrm{mV}$ & $\begin{array}{l}\text { Millivolt output from pyrheliometer, east } \\
\text { tracker position (when pointing south) }\end{array}$ & Average & $\mathrm{T}$ \\
\hline Pyrh1temp_C & $\mathrm{C}$ & $\begin{array}{l}\text { Pyrheliometer case temperature, east tracker } \\
\text { position (when pointing south) }\end{array}$ & Average & $\mathrm{T}$ \\
\hline Pyrh2_mV & $\mathrm{mV}$ & $\begin{array}{l}\text { Millivolt output from pyrheliometer, west } \\
\text { tracker position (when pointing south) }\end{array}$ & Average & $\mathrm{L}$ \\
\hline Qloss_Ah & $A \cdot h$ & Charge deficit of UPS battery & Max & $\mathrm{T} / \mathrm{L}$ \\
\hline Rain_mm & $\mathrm{mm}$ & Rain accumulation, piezoelectric sensor & Sum & $\mathrm{T}$ \\
\hline RainTB_mm & $\mathrm{mm}$ & $\begin{array}{l}\text { Rain and precipitation liquid equivalent } \\
\text { accumulation, tipping bucket gauge }\end{array}$ & Sum & $\mathrm{T}$ \\
\hline RefCell1_Wm2 & $\mathrm{W} / \mathrm{m}^{2}$ & $\begin{array}{l}\text { Irradiance from flat-plate silicon sensor, } 0^{\circ} \\
\text { tilt }\end{array}$ & Average & $\mathrm{T}$ \\
\hline RefCell2_Wm2 & $\mathrm{W} / \mathrm{m}^{2}$ & $\begin{array}{l}\text { Irradiance from flat-plate silicon sensor, } 10^{\circ} \\
\text { tilt, } 180^{\circ} \text { azimuth } \mathrm{CW} \text { from north }\end{array}$ & Average & $\mathrm{T}$ \\
\hline RefCell3_Wm2 & $\mathrm{W} / \mathrm{m}^{2}$ & $\begin{array}{l}\text { Irradiance from flat-plate silicon sensor, } 5^{\circ} \\
\text { tilt, } 270^{\circ} \text { azimuth CW from north }\end{array}$ & Average & $\mathrm{T}$ \\
\hline RefCell4_Wm2 & $\mathrm{W} / \mathrm{m}^{2}$ & $\begin{array}{l}\text { Irradiance from flat-plate silicon sensor, } 5^{\circ} \\
\text { tilt, } 90^{\circ} \text { azimuth CW from north }\end{array}$ & Average & $\mathrm{T}$ \\
\hline RefCell5_Wm2 & $\mathrm{W} / \mathrm{m}^{2}$ & $\begin{array}{l}\text { Irradiance from flat-plate silicon sensor, } 20^{\circ} \\
\text { tilt, } 180^{\circ} \text { azimuth } \mathrm{CW} \text { from north }\end{array}$ & Average & $\mathrm{T}$ \\
\hline RefCell6_Wm2 & $\mathrm{W} / \mathrm{m}^{2}$ & $\begin{array}{l}\text { Irradiance from flat-plate silicon sensor, } \\
18.4^{\circ} \text { tilt, } 180^{\circ} \text { azimuth } \mathrm{CW} \text { from north }\end{array}$ & Average & $\mathrm{T}$ \\
\hline RelayState & - & State of latching relay, bit field & Min & $\mathrm{T} / \mathrm{L}$ \\
\hline RelHumid & $\%$ & Relative humidity & Average & $\mathrm{T}$ \\
\hline RTD_C(1) & $\mathrm{C}$ & $\begin{array}{l}\text { Temperature of module backsheet: } 10^{\circ} \\
\text { tilted module, center }\end{array}$ & Average & $\mathrm{L}$ \\
\hline RTD_C(10) & $\mathrm{C}$ & $\begin{array}{l}\text { Temperature of module backsheet: } 5^{\circ} \text { east } \\
\text { tilted module, southwest }\end{array}$ & Average & $\mathrm{L}$ \\
\hline RTD_C(11) & $\mathrm{C}$ & $\begin{array}{l}\text { Temperature of module backsheet: } 5^{\circ} \text { east } \\
\text { tilted module, center-east }\end{array}$ & Average & $\mathrm{L}$ \\
\hline
\end{tabular}




\begin{tabular}{|c|c|c|c|c|}
\hline RTD_C(12) & $\mathrm{C}$ & $\begin{array}{l}\text { Temperature of module backsheet: } 5^{\circ} \text { east } \\
\text { tilted module, north-center }\end{array}$ & Average & $\mathrm{L}$ \\
\hline RTD_C(13) & $\mathrm{C}$ & $\begin{array}{l}\text { Temperature of module backsheet: } 20^{\circ} \\
\text { tilted module, center }\end{array}$ & Average & $\mathrm{L}$ \\
\hline RTD_C(14) & $\mathrm{C}$ & $\begin{array}{l}\text { Temperature of module backsheet: } 20^{\circ} \\
\text { tilted module, northeast }\end{array}$ & Average & $\mathrm{L}$ \\
\hline RTD_C(15) & $\mathrm{C}$ & $\begin{array}{l}\text { Temperature of module backsheet: } 20^{\circ} \\
\text { tilted module, center-west }\end{array}$ & Average & $\mathrm{L}$ \\
\hline RTD_C(16) & $\mathrm{C}$ & $\begin{array}{l}\text { Temperature of module backsheet: } 20^{\circ} \\
\text { tilted module, south-center }\end{array}$ & Average & $\mathrm{L}$ \\
\hline RTD_C(2) & $\mathrm{C}$ & $\begin{array}{l}\text { Temperature of module backsheet: } 10^{\circ} \\
\text { tilted module, northwest }\end{array}$ & Average & $\mathrm{L}$ \\
\hline RTD_C(3) & $\mathrm{C}$ & $\begin{array}{l}\text { Temperature of module backsheet: } 10^{\circ} \\
\text { tilted module, south-center }\end{array}$ & Average & $\mathrm{L}$ \\
\hline RTD_C(4) & $\mathrm{C}$ & $\begin{array}{l}\text { Temperature of module backsheet: } 10^{\circ} \\
\text { tilted module, center-east }\end{array}$ & Average & $\mathrm{L}$ \\
\hline RTD_C(5) & $\mathrm{C}$ & $\begin{array}{l}\text { Temperature of module backsheet: } 5^{\circ} \text { west } \\
\text { tilted module, center }\end{array}$ & Average & $\mathrm{L}$ \\
\hline RTD_C(6) & $\mathrm{C}$ & $\begin{array}{l}\text { Temperature of module backsheet: } 5^{\circ} \text { west } \\
\text { tilted module, northeast }\end{array}$ & Average & $\mathrm{L}$ \\
\hline RTD_C(7) & $\mathrm{C}$ & $\begin{array}{l}\text { Temperature of module backsheet: } 5^{\circ} \text { west } \\
\text { tilted module, center-west }\end{array}$ & Average & $\mathrm{L}$ \\
\hline RTD_C(8) & $\mathrm{C}$ & $\begin{array}{l}\text { Temperature of module backsheet: } 5^{\circ} \text { west } \\
\text { tilted module, south-center }\end{array}$ & Average & $\mathrm{L}$ \\
\hline RTD_C(9) & $\mathrm{C}$ & $\begin{array}{l}\text { Temperature of module backsheet: } 5^{\circ} \text { east } \\
\text { tilted module, center }\end{array}$ & Average & $\mathrm{L}$ \\
\hline SixInOneHeatStateID & - & 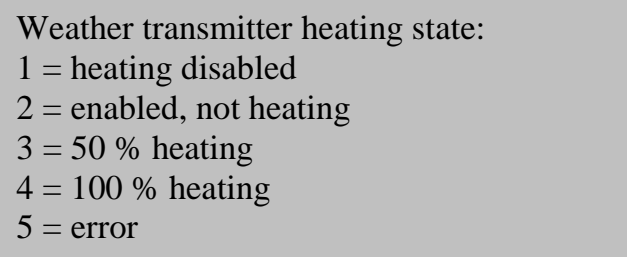 & Average & $\mathrm{T}$ \\
\hline SixInOneRef_V & $\mathrm{V}$ & $\begin{array}{l}\text { Internal reference voltage in weather } \\
\text { transmitter }\end{array}$ & Min & $\mathrm{T}$ \\
\hline SnowDepth_cm & $\mathrm{cm}$ & Snow depth & Average & $\mathrm{L}$ \\
\hline SolarAzFromSouth_deg & $\circ$ & Solar azimuth, CW from south & Average & $\mathrm{T} / \mathrm{L}$ \\
\hline SolarTime_hr & $\mathrm{h}$ & Solar time & Max, Median & $\mathrm{T} / \mathrm{L}$ \\
\hline SolarZenith_deg & $\circ$ & Solar zenith angle & Average & $\mathrm{T} / \mathrm{L}$ \\
\hline TC_C(1) & $\mathrm{C}$ & $\begin{array}{l}\text { Temperature of module backsheet: } 0^{\circ} \text { tilted } \\
\text { module, center }\end{array}$ & Average & $\mathrm{L}$ \\
\hline TC_C(2) & $\mathrm{C}$ & $\begin{array}{l}\text { Temperature of module backsheet: } 0^{\circ} \text { tilted } \\
\text { module, southeast }\end{array}$ & Average & $\mathrm{L}$ \\
\hline TC_C(3) & $\mathrm{C}$ & $\begin{array}{l}\text { Temperature of module backsheet: } 0^{\circ} \text { tilted } \\
\text { module, north-center }\end{array}$ & Average & $\mathrm{L}$ \\
\hline
\end{tabular}




\begin{tabular}{|c|c|c|c|c|}
\hline TC_C(4) & $\mathrm{C}$ & $\begin{array}{l}\text { Temperature of module backsheet: } 0^{\circ} \text { tilted } \\
\text { module, between center and southeast }\end{array}$ & Average & $\mathrm{L}$ \\
\hline TC_C (5) & $\mathrm{C}$ & $\begin{array}{l}\text { Temperature of module backsheet: } 18.4^{\circ} \\
\text { tilted module, center }\end{array}$ & Average & $\mathrm{L}$ \\
\hline TC_C(6) & $\mathrm{C}$ & $\begin{array}{l}\text { Temperature of module backsheet: } 18.4^{\circ} \\
\text { tilted module, northwest }\end{array}$ & Average & $\mathrm{L}$ \\
\hline TC_C(7) & $\mathrm{C}$ & $\begin{array}{l}\text { Temperature of module backsheet: } 18.4^{\circ} \\
\text { tilted module, south-center }\end{array}$ & Average & $\mathrm{L}$ \\
\hline TC_C $(8)$ & $\mathrm{C}$ & $\begin{array}{l}\text { Temperature of module backsheet: } 18.4^{\circ} \\
\text { tilted module, center-east }\end{array}$ & Average & $\mathrm{L}$ \\
\hline TIMESTAMP & LST & Date and time & Max & $\mathrm{T} / \mathrm{L}$ \\
\hline TrackerFlags & - & Tracker status, bit field & Max & $\mathrm{L}$ \\
\hline TrackerState & - & Tracker state & Min & $\mathrm{L}$ \\
\hline UVA_mV & $\mathrm{mV}$ & $\begin{array}{l}\text { Millivolt output from UV-A radiometer } \\
\text { converter box }\end{array}$ & Average & $\mathrm{T}$ \\
\hline UVB_mV & $\mathrm{mV}$ & $\begin{array}{l}\text { Millivolt output from UV-B radiometer } \\
\text { converter box }\end{array}$ & Average & $\mathrm{T}$ \\
\hline UVBtemp_C & $\mathrm{C}$ & $\begin{array}{l}\text { UV-B radiometer optical system } \\
\text { temperature }\end{array}$ & Average & $\mathrm{T}$ \\
\hline UVT_mV & $\mathrm{mV}$ & Millivolt output from UV total radiometer & Average & $\mathrm{L}$ \\
\hline Vent2_rpm & $\mathrm{rev} / \mathrm{min}$ & $\begin{array}{l}\text { Mean GHI ventilator fan speed, south table } \\
\text { position }\end{array}$ & Average* & $\mathrm{T}$ \\
\hline Vent4_rpm & $\mathrm{rev} / \mathrm{min}$ & $\begin{array}{l}\text { Mean GHI ventilator fan speed, north table } \\
\text { position }\end{array}$ & Average* & $\mathrm{L}$ \\
\hline WindDir_deg & $\circ$ & $\begin{array}{l}\text { Wind direction } 5.72 \mathrm{~m} \text { above roof, } \\
\text { clockwise from north }\end{array}$ & - & $\mathrm{T}$ \\
\hline WindDir1_deg & $\circ$ & $\begin{array}{l}\text { Wind direction } 2.51 \mathrm{~m} \text { above roof, } \\
\text { clockwise from north }\end{array}$ & - & $\mathrm{L}$ \\
\hline WindDir1Ave_deg & $\circ$ & $\begin{array}{l}\text { Unit vector mean wind direction } 2.51 \mathrm{~m} \\
\text { above roof }\end{array}$ & Average* & $\mathrm{L}$ \\
\hline WindDirAve_deg & $\circ$ & $\begin{array}{l}\text { Unit vector mean wind direction } 5.72 \mathrm{~m} \\
\text { above roof }\end{array}$ & Average* & $\mathrm{T}$ \\
\hline WindDirStdDev_deg & $\circ$ & $\begin{array}{l}\text { Standard deviation of the wind direction; } \\
\text { Top: } \quad 5.72 \mathrm{~m} \text { above roof } \\
\text { Lower: } \quad 2.51 \mathrm{~m} \text { above roof }\end{array}$ & Std. Dev.* & $\mathrm{T} / \mathrm{L}$ \\
\hline WindSpeed_ms & $\mathrm{m} / \mathrm{s}$ & Wind speed $5.72 \mathrm{~m}$ above roof & Max & $\mathrm{T}$ \\
\hline WindSpeed1_ms & $\mathrm{m} / \mathrm{s}$ & Wind speed $2.51 \mathrm{~m}$ above roof & Max & $\mathrm{L}$ \\
\hline WindSpeed1Ave_ms & $\mathrm{m} / \mathrm{s}$ & $\begin{array}{l}\text { Mean horizontal wind speed } 2.51 \mathrm{~m} \text { above } \\
\text { roof }\end{array}$ & Average* & $\mathrm{L}$ \\
\hline WindSpeedAve_ms & $\mathrm{m} / \mathrm{s}$ & $\begin{array}{l}\text { Mean horizontal wind speed } 5.72 \mathrm{~m} \text { above } \\
\text { roof }\end{array}$ & Average* & $\mathrm{T}$ \\
\hline
\end{tabular}




\begin{tabular}{lll} 
& Wind sensor $5.72 \mathrm{~m}$ above roof data & \\
WindValid & validity & Average \\
& $-1=$ wind data is valid & \\
& $0=$ wind data is invalid & \\
\hline
\end{tabular}

Note: All measurements are sampled every $1 \mathrm{~s}$ except the RTDs and thermocouples, which are sampled every $10 \mathrm{~s}$. All measurements are saved every $1 \mathrm{~s}$, except those marked with a “*”.

* Calculated from saved $1 \mathrm{~s}$ samples; only the 1 min aggregate data are saved 
Appendix B. Module Data Sheets

\section{SIEMENS}

\section{MODEL SP160-CPL}

PHOTOVOLTAIC MODULE

\section{$\mathrm{CH}_{\mathrm{us}}$}

SPECIFICATIONS AT $1000 \mathrm{~W} \mathrm{M}^{2}$ SOLAR IRRADIANCE, $25^{\circ} \mathrm{C}$ CELL TEMPERATURE.

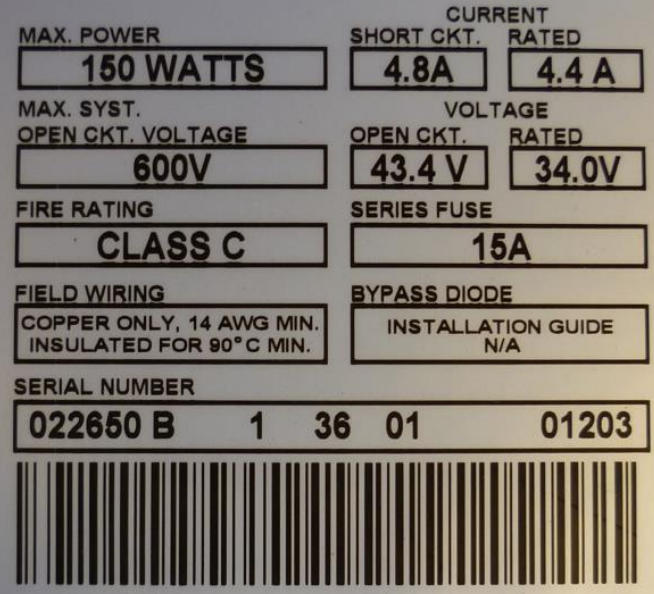

\section{Siemens Solar Industries}

\section{Camarillo, CA 93011-6032}

\section{WARNING / ELECTRICAL HAZARD}

BEFORE ATTEMPTING TO INSTALL, USE AND MAINTAIN THIS PRODUCT, READ, UNDERSTAND AND FOLLOW ALL SAFETY PRECAUTIONS DETAILED IN THE INSTRUCTION MANUAL. THIS MODULE PRODUCES ELECTRICITY WHEN EXPOSED TO SUNLIGHT. THIRTY VOLTS OA GREATER IS CONSIDERED A SHOCK HAZARD. DO NOT CONTACT TERMINALS WHEN MODULE IS EXPOSED TO SUNLIGHT. DO NOT PRODUCE SPARKS NEAR FLAMMABLE VAPORS. FOLLOW SAFETY PRECAUTIONS OF THE BATTERY MANUFACTURER IF BATTERIES ARE USED WITH MODULES. DO NOT POUR LIOUIDS ON MODULES WHEN CLEANING. DO NOT IMMERSE IN LIQUIDS. DO NOT WEAR JEWELRY DO NOT SHADOW CELLS. DO NOT EXPOSE MODULE TO CONCENTRATED SUNLIGHT WITH MIRRORS, LENSES OR SIMILAR MEANS. INSTALL MODUIE AND GROUND FRAMES IN ACCORDANCE WITH LOCAL CODES OR THE NATIONAL EIECTRICAL CODE. INSPECTION PEOUIREMENTS, CONSULT MANUFACTURER FOR PROPER INSTALLATION ON SPECIAL VEHICLES SUCH AS CONTS AND CAMPERS. PRODUCT SHOULD BE INSTALLED A AND CAMPERS. AND MAINTAINED BY QUALIFIED PERSGQQNUEIN US KEEP MODULE AWAY FROM CHILDREN.

Figure B-1 Picture of Horizontal PV Reference Module Nameplate 
Appendix B. Module Data Sheets

\section{WATT}

NU-U235F2

NEC 2008 Compliant

Module output cables: 12 AWG PV Wire

\begin{tabular}{|c|c|c|}
\hline \multicolumn{3}{|c|}{ ELECTRICAL CHARACTERISTICS } \\
\hline \multicolumn{2}{|l|}{ Maximum Power (Pmax)* } & $235 \mathrm{~W}$ \\
\hline \multicolumn{2}{|l|}{ Tolerance of Pmax } & $+10 \% /-5 \%$ \\
\hline \multicolumn{2}{|l|}{ Type of Cell } & Monocrystalline silicon \\
\hline \multicolumn{2}{|l|}{ Cell Configuration } & 60 in series \\
\hline \multicolumn{2}{|l|}{ Open Circuit Voltage (Voc) } & $37.0 \mathrm{~V}$ \\
\hline \multicolumn{2}{|l|}{ Maximum Power Voltage (Vpm) } & $30.0 \mathrm{~V}$ \\
\hline \multicolumn{2}{|l|}{ Short Circuit Current (Isc) } & $8.60 \mathrm{~A}$ \\
\hline \multicolumn{2}{|l|}{ Maximum Power Current (Ipm) } & $7.84 \mathrm{~A}$ \\
\hline \multicolumn{2}{|l|}{ Module Efficiency (\%) } & $14.4 \%$ \\
\hline \multicolumn{2}{|l|}{ Maximum System (DC) Voltage } & $600 \mathrm{~V}$ \\
\hline \multicolumn{2}{|l|}{ Series Fuse Rating } & $15 \mathrm{~A}$ \\
\hline \multicolumn{2}{|l|}{ NOCT } & $47.5^{\circ} \mathrm{C}$ \\
\hline \multicolumn{2}{|l|}{ Temperature Coefficient (Pmax) } & $-0.485 \% /{ }^{\circ} \mathrm{C}$ \\
\hline \multicolumn{2}{|l|}{ Temperature Coefficient (Voc) } & $-0.351 \% /{ }^{\circ} \mathrm{C}$ \\
\hline \multicolumn{2}{|l|}{ Temperature Coefficient (Isc) } & $0.053 \% /{ }^{\circ} \mathrm{C}$ \\
\hline \multicolumn{3}{|c|}{$\begin{array}{l}\text { 'Illumination of } 1 \mathrm{~kW} / \mathrm{m}^{2}(1 \text { sun) at spectral distribution of AM } 1.5 \text { (ASTM E892 } \\
\text { global spectral irradiance) at a cell temperature of } 25^{\circ} \mathrm{C} \text {. }\end{array}$} \\
\hline \multicolumn{3}{|c|}{ MECHANICAL CHARACTERISTICS } \\
\hline Dimensions ( $\mathrm{A} \times \mathrm{B} \times \mathrm{C}$ below) & \multicolumn{2}{|c|}{$39.1 " \times 64.6 " \times 1.8 " / 994 \times 1640 \times 46 \mathrm{~mm}$} \\
\hline Cable Length (G) & \multicolumn{2}{|c|}{$43.3^{\prime \prime} / 1100 \mathrm{~mm}$} \\
\hline Output Interconnect Cable ${ }^{+*}$ & \multicolumn{2}{|c|}{12 AWG with MC4 Locking Connector } \\
\hline Weight & \multicolumn{2}{|c|}{$41.9 \mathrm{lbs} / 19.0 \mathrm{~kg}$} \\
\hline Max Load & \multicolumn{2}{|c|}{50 psf (2400 Pascals) } \\
\hline Operating Temperature (cell) & \multicolumn{2}{|c|}{-40 to $194^{\circ} \mathrm{F} /-40$ to $90^{\circ} \mathrm{C}$} \\
\hline \multicolumn{3}{|c|}{$\begin{array}{l}\text { "*A safety lock clip (Multi Contact part number PV-SSH4) may be required in } \\
\text { readily accessible locations per NEC } 2008690.33 \text { (C) } \\
\text { "*PV Wire per UL Subject } 4703\end{array}$} \\
\hline \multicolumn{3}{|l|}{ QUALIFICATIONS } \\
\hline UL Listed & \multicolumn{2}{|c|}{ UL 1703} \\
\hline Fire Rating & \multicolumn{2}{|c|}{ Class C } \\
\hline \multicolumn{3}{|l|}{ WARRANTY } \\
\hline \multicolumn{3}{|c|}{$\begin{array}{l}\text { 25-year limited warranty on power output } \\
\text { Contact Sharp for complete warranty information }\end{array}$} \\
\hline \multicolumn{3}{|c|}{$\begin{array}{l}\text { lesign and specifications are subject to change without notice. } \\
\text { hirp is a registered trademark of Sharp Corporation. All other trademarks are property of } \\
\text { heir respective owners. Contact Sharp to obtain the latest product manuals before using } \\
\text { ny Sharp device. Cover photo: Solar Installation by SPG Solar. }\end{array}$} \\
\hline
\end{tabular}


Contact Sharp for tolerance specifications

\section{"BUY AMERICAN"}

Sharp solar modules are manufactured in the United States and Japan, and qualify as "American" goods under the "Buy American" clause of the American Recovery and Reinvestment Act (ARRA).

\section{SHARP}

C 2010 Sharp Electronics Corporation. All rights reserved.
SHARP ELECTRONICS CORPORATION

5901 Bolsa Avenue, Huntington Beach, CA 92647

1-800-SOLAR-06•Email: sharpsolar@sharpusa.com

www.sharpusa.com/solar

Figure B-2 Manufacturer Datasheet for the $5^{\circ}, 10^{\circ}$, and $20^{\circ}$ Tilted PV Reference Modules 


\section{SUNPOWER}

\section{E19 / 320 SOLAR PANEL \\ MAXIMUM EFFICIENCY AND PERFORMANCE}

\begin{tabular}{|c|c|c|}
\hline \multicolumn{3}{|c|}{ Electrical Data } \\
\hline Peak Power $(+5 /-3 \%)$ & $P_{\max }$ & $320 \mathrm{~W}$ \\
\hline Efficiency & $\eta$ & $19.6 \%$ \\
\hline Rated Voltage & $V_{m p p}$ & $54.7 \mathrm{~V}$ \\
\hline Rated Current & Impp & $5.86 \mathrm{~A}$ \\
\hline Open Circuit Voltage & $v_{o c}$ & $64.8 \mathrm{~V}$ \\
\hline Short Circuit Current & $\mathrm{I}_{\mathrm{sc}}$ & $6.24 \mathrm{~A}$ \\
\hline Maximum System Voltage & UL & $600 \mathrm{~V}$ \\
\hline \multirow[t]{3}{*}{ Temperature Coefficients } & Power (P) & $-0.38 \% / \mathrm{K}$ \\
\hline & Voltage $\left(V_{\text {oc }}\right)$ & $-176.6 \mathrm{mV} / \mathrm{K}$ \\
\hline & Current $\left.\|_{\text {sc }}\right)$ & $3.5 \mathrm{~mA} / \mathrm{K}$ \\
\hline NOCT & & $45^{\circ} \mathrm{C}+1-2^{\circ} \mathrm{C}$ \\
\hline Series Fuse Rating & & $20 \mathrm{~A}$ \\
\hline
\end{tabular}

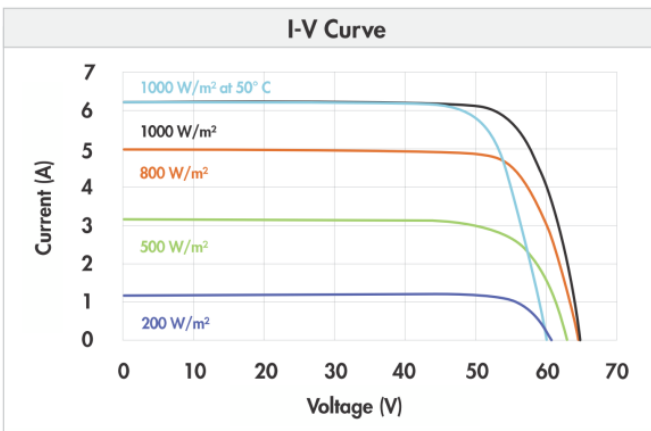

Current/voltage characteristics with dependence on irradiance and module temperature.

\begin{tabular}{|l|l|}
\hline \multicolumn{1}{|c|}{ Tested Operating Conditions } \\
\hline Temperature & $-40^{\circ} \mathrm{F}$ to $+185^{\circ} \mathrm{F}\left(-40^{\circ} \mathrm{C}\right.$ to $\left.+85^{\circ} \mathrm{C}\right)$ \\
\hline Max load & $\begin{array}{l}\left.113 \text { psf } 550 \mathrm{~kg} / \mathrm{m}^{2}(5400 \mathrm{~Pa}) \text {, front (e.g. snow }\right) \\
\text { w } / \text { specified mounting configurations } \\
50 \text { psf } 245 \mathrm{~kg} / \mathrm{m}^{2}(2400 \mathrm{~Pa}) \text { front and back - e.g. } \\
\text { wind }\end{array}$ \\
\hline Impact Resistance Hail 1 in $(25 \mathrm{~mm})$ at $51 \mathrm{mph}(23 \mathrm{~m} / \mathrm{s})$ \\
\hline
\end{tabular}

Solar Cells 96 SunPower all-back contact monocrystalline

Front Glass High transmission tempered glass with anti-reflective (AR) coating

Junction Box IP-65 rated with 3 bypass diodes Dimensions: $32 \times 155 \times 128(\mathrm{~mm})$

Output Cables $1000 \mathrm{~mm}$ length cables / MultiContact (MC4) connectors Anodized aluminum alloy type 6063

Frame (black)

Weight $\quad 41.0 \mathrm{lbs}(18.6 \mathrm{~kg})$

\begin{tabular}{|c|c|}
\hline & Warranties and Certifications \\
\hline Warranties & 25 year limited power warranty \\
\hline & 10 year limited product warranty \\
\hline Certifications & Tested to UL. 1703. Class C Fire Rating \\
\hline
\end{tabular}

Dimensions

$\rightarrow$ Grounding Holes

$\underset{(\mathbb{N})}{M M}$


1559
$61.39]$
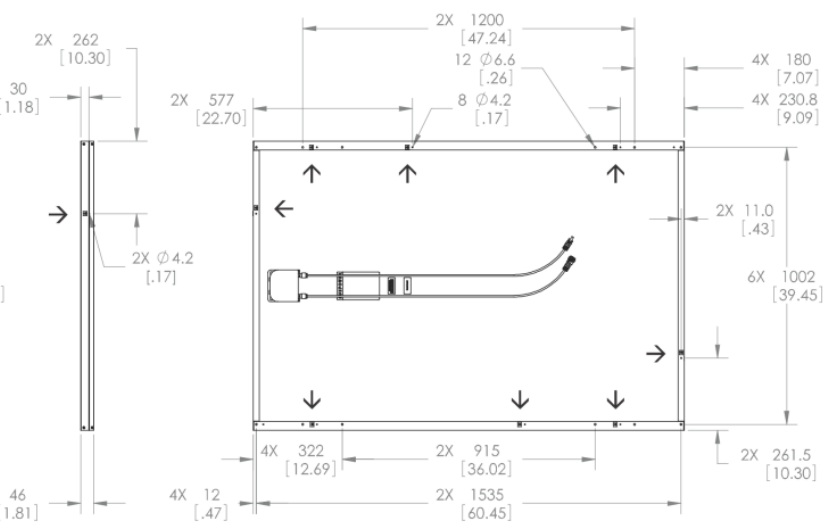

CAUTION: READ SAFETY AND INSTALLATION INSTRUCTIONS BEFORE USING THE PRODUCT. Visit sunpowercorp.com for details

Figure B-3 Manufacturer Datasheet for the $18.4^{\circ} \mathrm{PV}$ Reference Module 